\title{
Inverse modeling and forecasting for the exploitation of the Pauzhetsky geothermal field, Kamchatka, Russia
}

\author{
Alexey V. Kiryukhin ${ }^{1, *}$, Natalia P. Asaulova ${ }^{2}$, and Stefan Finsterle ${ }^{3}$ \\ ${ }^{1}$ Institute of Volcanology and Seismology FEB RAS, Piip-9, P-Kamchatsky, Russia 683006 \\ ${ }^{2}$ Kamchatskburgeotemia Enterprise, Krasheninnikova-1, Thermalny, Kamchatka, Russia, 684035 \\ ${ }^{3}$ Lawrence Berkeley National Laboratory, 1 Cyclotron Rd., Berkeley, CA 94720, USA
}

\begin{abstract}
A three-dimensional numerical model of the Pauzhetsky geothermal field has been developed based on a conceptual hydrogeological model of the system. It extends over a 13.6$\mathrm{km}^{2}$ area and includes three layers: (1) a base layer with inflow; (2) a geothermal reservoir; and (3) an upper layer with discharge and recharge/infiltration areas. Using the computer program iTOUGH2 (Finsterle, 2004), the model is calibrated to a total of 13,675 calibration points, combining natural-state and 1960-2006 exploitation data. The principal model parameters identified and estimated by inverse modeling include the fracture permeability and fracture porosity of the geothermal reservoir, the initial natural upflow rate, the base-layer porosity, and the permeabilities of the infiltration zones. Heat and mass balances derived from the calibrated model helped identify the sources of the geothermal reserves in the field. With the addition of five makeup wells, simulation forecasts for the 2007-2032 period predict a sustainable average steam production of $29 \mathrm{~kg} / \mathrm{s}$, which is sufficient to maintain the generation of $6.8 \mathrm{MWe}$ at the Pauzhetsky power plant.
\end{abstract}

Keywords: Geothermal; Production forecast; Inverse modeling; Pauzhetsky; Russia

\footnotetext{
* Corresponding author: Tel.: + 7415225 9543; fax: + 74152254723

E-mail address: e-mail: avk2@kscnet.ru (A.V. Kiryukhin)
} 


\section{Nomenclature}

$\mathrm{c}_{\mathrm{Cl}} \quad$ chloride concentration [ppm]

$\mathrm{c}_{\mathrm{s}} \quad$ chloride concentration after separation [ppm]

C compressibility $\left[\mathrm{Pa}^{-1}\right]$

h enthalpy $[\mathrm{kJ} / \mathrm{kg}]$

$\mathrm{H}$ reservoir thickness [m]

$\mathrm{k} \quad$ permeability $[\mathrm{mD}]$

$\mathrm{k}_{\mathrm{i}} \quad$ Upper-layer "hydraulic window" permeability; i = N, E, W [mD]

$\mathrm{P} \quad$ pressure [bar]

Q mass flow rate $[\mathrm{kg} / \mathrm{s}]$

$\mathrm{T} \quad$ temperature $\left[{ }^{\circ} \mathrm{C}\right]$

Greek symbols

$\phi \quad$ porosity

$\rho \quad$ fluid density $\left[\mathrm{kg} / \mathrm{m}^{3}\right]$

Subscripts

b base-layer upflow zone

$\mathrm{BH}$ bottomhole

P pressure

r reservoir

Q flow rate

$\mathrm{T}$ temperature 


\section{Introduction}

The development of the Pauzhetsky geothermal field located in the Kamchatka Peninsula of Far East Russia began in 1960. In 1966, a 5-MWe power plant was put into operation, which was replaced in 2006 by a new 6-MWe unit. The first reservoir engineering studies of the field (Piip, 1965; Sugrobov, 1970) revealed a liquid-dominated reservoir in layered tuffs at temperatures of $170-190^{\circ} \mathrm{C}$, with hot springs discharges at $31 \mathrm{~kg} / \mathrm{s}$. The first 10 years of exploitation at a total mass rate of $160-190 \mathrm{~kg} / \mathrm{s}$ showed a gradual temperature decline and chloride dilution in the fluids produced by wells located near the natural discharge area.

Consequently, new exploration and development wells were drilled, and exploitation gradually shifted away from the natural discharge area until fluid temperatures of $200-220^{\circ} \mathrm{C}$ were reached. Production wells were drilled into a central upflow zone located $1.5-2.0 \mathrm{~km}$ southeast of the old production field. The drop in temperatures and enthalpies continued, while the total mass flow rate reached $220-260 \mathrm{~kg} / \mathrm{s}$ between 1975 and 2006 .

The forward TOUGH $2^{1}$ modeling study by Kiryukhin and Yampolsky (2004) had difficulties in identifying and estimating the principal parameters of the geothermal system, and in matching the large collection of data amassed during 36 years of exploitation. Thus, in this study we employ iTOUGH $2^{2}$ inverse modeling to help verify the conceptual hydrogeological model of the system, to identify key parameters, and to obtain more reliable parameter estimates and subsequent predictions.

\section{Conceptual hydrogeologic models}

The Pauzhetsky geothermal system is situated within the Pauzhetka volcano-tectonic depression of the Kamchatka Peninsula (Fig. 1). Figure 2 shows the well field, the footprint of the presumed upflow zone as indicated by low electrical conductivity areas and surface manifestations (hot springs, fumaroles, and hot ground areas with a temperature above $20^{\circ} \mathrm{C}$ at a depth of $1 \mathrm{~m}$ ), as well as a plan view of the computational mesh.

The hydrogeological model for the system is presented in Fig. 3 (see also Kiryukhin et al., 2006). Cold meteoric water infiltrates to a depth of 5-6 km into a zone with temperatures above $250^{\circ} \mathrm{C}$, where it heats up and begins flowing upward. The high-temperature ascending fluids, with enthalpies of 950-1050 kJ/kg, reach the volcanogenic-sedimentary basin (consisting of $\mathrm{N}_{2^{-}}$

${ }^{1}$ TOUGH2 is a general-purpose numerical simulation program for multi-phase fluid and heat flow in porous and fractured media. The simulator was developed in the Earth Sciences Division of Lawrence Berkeley National Laboratory for applications in geothermal reservoir engineering, nuclear waste disposal, unsaturated zone hydrology, environmental remediation, and geologic storage of $\mathrm{CO}_{2}$. More information can be found at http://www-esd.lbl.gov/TOUGH2.

2 iTOUGH2 (inverse TOUGH2) is a computer program that provides inverse modeling capabilities for the TOUGH2 suite of simulators; it solves the inverse problem by automatically calibrating a TOUGH2 model against observed data. Any TOUGH2 input parameter can be estimated based on any observation for which a corresponding TOUGH2 output can be calculated. An objective function measures the difference between the model calculation and the observed data, and a minimization algorithm proposes new parameter sets that iteratively improve the match. Once the best estimate parameter set is identified, iTOUGH2 performs an extensive error analysis, which provides statistical information about residuals, estimation uncertainties, and the ability to discriminate among model alternatives. Furthermore, an uncertainty propagation analysis allows one to quantify prediction errors. More information can be found at http://www-esd.lbl.gov/iTOUGH2. 
$\mathrm{Q}_{1}$ welded tuffs, tufaceous conglomerates, and psephitic tuffs) that hosts a multi-layered geothermal reservoir.

An integrated analysis of the field data shows the Pauzhetsky geothermal reservoir has the following characteristics:

(1) It is layered, extends over an area of at least $2 \mathrm{~km} \times 2.5 \mathrm{~km}$ and has an average thickness of $500 \mathrm{~m}$. The reservoir is being recharged by the upflowing hot fluids; this information is based mainly on data from 67 wells and a resistivity survey. Cumulative production rate per well versus depth shows that most fluids are produced from the depth interval between -50 and $-550 \mathrm{~m}$ above sea level ( $\mathrm{m}$ asl). This interval includes the lower and middle parts of the Pauzhetka Tuff $\left(\mathrm{N}_{2}-\mathrm{Q}_{1}\right.$ pau $\left.{ }_{1,2}\right)$ and the Golyginsky Layer $\left(\mathrm{N}_{2}\right.$ gol $)$; see Fig. 3. This is a clear indication of the layered permeability structure of the reservoir.

(2) Well logs from 67 wells (an example is shown in Fig. 4) and their analyses show the effects of discrete features on reservoir behavior. For the coarsely discretized model of Fig. 2, the impact of fracture zones is included using a double-porosity approach (Pruess and Narasimhan, 1985), with a fracture volume fraction of 0.28 and an average fracture spacing of $105 \mathrm{~m}$. The "fracture volume" corresponds to the high-permeability, unwelded top and bottom tuff and lava flow units, while the "matrix volume" corresponds to the interior part of the reservoir, which consists of low-permeability, welded tuffs and lava flow units. This is a generic feature of many pyroclastic flow formations, with the interior part welded under high pressures and temperatures, while the exterior parts are unwelded as a result of fast cooling under lowpressure conditions. According to this model, the relatively high fracture volume fraction reflects the ratio between unwelded and welded units, rather than the volume fraction of individual fractures.

The location of the major production zones was determined based on data from 31 wells, which intersected 146 of them. They included 55 contact zones between different stratigraphic units, 41 zones within the lower and middle parts of the Pauzhetka Tuff, 15 zones within the Golyginsky Layer, and seven zones within the Miocene sandstone rocks. Secondary mineral distributions in wells show that laumontite correlates with the high-permeability (i.e. production) zones in the reservoir, whereas calcite-chlorite-smectites correlate with the low-permeability zones (Korobov et al., 1989). These mineral distributions are consistent with a double-porosity conceptual model.

(3) The initial (natural) discharge of the system from hot boiling springs was $31 \mathrm{~kg} / \mathrm{s}$ (Piip, 1965; Sugrobov, 1970).

(4) From semi-log analyses of multiwell flowtest data we estimated that the permeabilitythickness $(\mathrm{kH})$ of the production zone ranged between 35 and $94 \mathrm{Dm}$ and that its total compressibility was $9.0 \times 10^{-6} \mathrm{~Pa}^{-1}$. Laboratory testing of samples of reservoir rock matrix show a porosity of up to 0.2 , a bulk density of $1500-1800 \mathrm{~kg} / \mathrm{m}^{3}$ (Ladygin et al., 2000), and an average heat conductivity (under dry conditions) of $1.6 \mathrm{~W} / \mathrm{m}^{\circ} \mathrm{C}$ (Yanovsky, 1989).

(5) The initial reservoir pressure is $34.5-35.5$ bar at $-250 \mathrm{~m}$ asl. In the northern part of the field the pressure tends to increase in a south-easterly direction.

(6) The initial production reservoir temperature is $180-220^{\circ} \mathrm{C}$; the upflow zone is approximately delineated by the $190^{\circ} \mathrm{C}$ isotherm within the drilled part of the field. The Dacite Extrusion Complex $\left(\mathrm{Q}_{2-3}\right)$ inside the $190^{\circ} \mathrm{C}$ zone acts as a structural control for the temperature and permeability distributions.

The initial chemistry of the produced geothermal fluids is characterized by its $\mathrm{NaCl}$ and $\mathrm{CO}_{2}-\mathrm{N}_{2}$ contents, with a total dissolved solids of $2.7-3.4 \mathrm{~g} / \mathrm{kg}$, and a non-condensable gas content of $0.04-0.08 \%$ (by weight). The stable isotopic $\left(\delta \mathrm{D}, \delta^{18} \mathrm{O}\right)$ composition of the hot fluids corresponds to the range measured in Kurile Lake waters (at $110 \mathrm{~m}$ asl) and in the cold springs at 
the Kambalny Ridge (at 600-700 m asl), which demonstrates their meteoric origin (Kiryukhin and Sugrobov, 1987).

The fluid enthalpy versus chloride diagram (Fig. 5) illustrates the integrated effect of reservoir-fluid dilution and reservoir temperature decline during exploitation. The chloride concentrations $\left(\mathrm{c}_{\mathrm{Cl}}\right)$ were corrected to compensate for steam loss according to

$$
\mathrm{c}_{\mathrm{Cl}}=\mathrm{c}_{\mathrm{s}} \cdot(2680-\mathrm{h}) /(2680-419)
$$

where $c_{s}$ is the chloride concentration after separation (in ppm), and $h$ is the enthalpy (in $\mathrm{kJ} / \mathrm{kg}$ ). All trace elements reflect the geothermal source fluid, which was estimated to have a chloride concentration of $1600 \mathrm{ppm}$ and an enthalpy of $870 \mathrm{~kJ} / \mathrm{kg}$ (corresponding to $204^{\circ} \mathrm{C}$ ). The downward pointing arrows in Fig. 5 indicate dilution by meteoric inflows. The most diluted wells are 106, 108, and RE1, where the meteoric water fraction is estimated to be $40-62.5 \%$, and the fluid enthalpy drops to $680-730 \mathrm{~kJ} / \mathrm{kg}$. Wells $121,122,123$ and 103 are less sensitive to meteoric water inflows; the dilution rate is estimated to be $30-39.5 \%$, and the enthalpy decline to $740-850 \mathrm{~kJ} / \mathrm{kg}$. Wells GK3 and 120 indicate a dilution of 13 to $39.5 \%$, with fluid enthalpies in the $790-890 \mathrm{~kJ} / \mathrm{kg}$ range, and a relatively slow decline rate. Stable isotope data $\left(\delta \mathrm{D}, \delta^{18} \mathrm{O}\right)$ and tritium data confirm significant meteoric inflow into the geothermal reservoir during exploitation.

Hence, the key feature of the behavior of the Pauzhetsky field is the cooling of the production wells, accompanied by a change in fluid chemistry and temperatures along predominantly horizontal streamlines that begin at the recharge areas. The cooling rates can be approximately correlated with the relative horizontal distances between the producing wells and the recharge areas, rather than the depths of the feed zones in the wells. For example, wells 106, 108 , and RE1, which are located closer to the recharge areas, show faster enthalpy and chloride declines compared to wells 121,122, 123 and 103, which are farther away from infiltration zones. The distinctly different dilution behavior of these two groups of wells is qualitatively consistent with the (horizontal) distribution of major production zones in the geothermal system as inferred from 31 wells, and the relative distances between major infiltration zones of meteoric water (northern infiltration area; see Figs. 6 and 7) and the production wells. This conceptual framework of (1) major flow paths in the system, (2) location of feed zones in the wells, (3) cold-water recharge zones, and (4) relative distances among these features, is implemented in the design of the computational mesh (see below).

The location of meteoric water inflows basically coincides with pre-exploitation discharge areas, i.e., fractured and/or faulted zones that allow hydraulic communication between the geothermal reservoir and the water-saturated alluvial deposits of the Pauzhetka River and tributary creeks. The pressure drop caused by exploitation turned these areas into distinct infiltration/recharge zones in the northern, western, and eastern parts of the field, surrounding the production zone in the center (see Fig. 8). There is also a possibility that some abandoned, poorly cemented wells allow the inflow of shallow groundwater into the geothermal reservoir. This is confirmed by the geochemical data discussed above, and is consistent with the specific spatial features of the geothermal reservoir as summarized in Figs. 6-8.

\section{Numerical model setup}

A highly simplified, three-dimensional numerical model of the Pauzhetsky field was constructed based on the conceptual hydrogeological model described in the previous section. The heat and mass flow calculations were done using the TOUGH2 simulator (Pruess et al., 1999).

The main features of the geologic and geothermal structure of the field were incorporated into the numerical model by connecting the layered geothermal reservoir to the "hydraulic windows" in the upper part of the computational mesh, and by allowing hot fluid recharge through the bottom of the mesh. Hence, the numerical model consists of three layers, i.e. (1) a base layer 
with permeable zones for hot-fluid recharge; (2) a middle layer that includes the geothermal reservoir, located at an average elevation of $-250 \mathrm{~m}$ asl, with an average thickness of $500 \mathrm{~m}$, a fracture spacing of $105 \mathrm{~m}$, a fracture/matrix ratio of $0.3 / 0.7$, and a planar area of $13.6 \mathrm{~km}^{2}$; and (3) an upper layer (caprock) with permeable regions to allow fluid recharge and discharge (see Figs. 6 and 7).

\subsection{Grid generation}

The geothermal reservoir was represented in the model as a coarsely discretized, three-layer system that covers the existing well field; it includes the three main layers just described; the surface grid is shown in Fig. 2. The preprocessor AMESH (Haukwa, 1998) was used to generate the computational grid. The model has 424 elements, a sufficiently small number that allows for a relatively efficient inverse modeling study. It is recognized that this discretization is too coarse to accurately capture all the features contributing to the responses of individual wells. Furthermore, the degree to which resulting discretization errors can be compensated through the estimation of effective parameters is limited. Nevertheless, this simplified model is considered appropriate for a first-order resource estimation. The insight gained from this preliminary forward and inverse modeling analysis provides the basis for future model refinements and a more accurate resource estimation.

\subsection{Double-porosity conversion}

The elements of the middle layer representing the geothermal reservoir were processed using 1D MINC (Multiple Interacting Continua; Pruess and Narasimhan, 1985) to introduce doubleporosity conditions with a fracture spacing of $105 \mathrm{~m}$ and a specific fracture volume of 0.3 , which represents the multilayered system consisting of welded ("matrix") and unwelded ("fractures") pyroclastic tuffs and lava units.

\subsection{Boundary conditions}

Mass sources were introduced into the base layer of the model, where the natural hightemperature upflows were assumed to occur, with enthalpies in the range $950-1050 \mathrm{~kJ} / \mathrm{kg}$, corresponding to liquid water temperatures of $220-240^{\circ} \mathrm{C}$. Heat sources were assigned at the base layer of the model to reproduce background conductive heat flow $\left(0.063 \mathrm{~W} / \mathrm{m}^{2}\right)$. Lateral noflow boundaries were also assigned. Discharge and recharge were specified as Dirichlet boundary conditions at the land surface, with a constant atmospheric pressure and temperatures of $100^{\circ}$ and $5^{\circ} \mathrm{C}$ for discharge and recharge zones, respectively. During exploitation, recharge of meteoric water and discharge through hot springs was simulated by vertically connecting surface elements to the mid-layer geothermal reservoir. Specifying a constant surface temperature of $5^{\circ} \mathrm{C}$ induced the conductive heat loss from the geothermal reservoir through the caprock.

\subsection{Zonation and rock properties}

The model was subdivided into several domains to represent major discharge and recharge zones (referred to as "hydraulic windows" in the caprock). The mid-layer geothermal reservoir was subdivided into a central part (ROCK1), boundary parts (ROCK4), and an internal, relatively impermeable domain (ROCK2). The base layer was divided into the upflow zone domain (BASE2) and host rock (BASE1). Formation properties are summarized in Table 1; permeabilities are assumed to be isotropic.

\section{Model parameterization}

The computer program iTOUGH 2 enables a modeler to estimate all parameters that are included in a TOUGH2 input data set, provided that sufficient data with appropriate sensitivities are available. A careful analysis is performed to keep the list of parameters to be estimated as short as possible, consistent with the simplicity of the conceptual model. The groups of parameters removed from the estimated parameters list are,

1. All parameters estimated from laboratory measurements (e.g. heat conductivity, rock specific heat, matrix porosity and matrix permeability), 
2. All parameters defined from well logging data (e.g. fracture spacing, relative fracture volume),

3. Measured production and injection well flow rates, and

4. Enthalpies of ascending fluid flows, which are inferred from geothermometers and temperature log data.

Any type of observed data for which a corresponding TOUGH2 output is calculated can be used as calibration data in an iTOUGH2 inversion. The only field data available on the Pauzhetsky geothermal field that we can use are: (1) enthalpy of produced fluids, (2) temperature logs in monitoring wells, (3) water levels in monitoring wells, and (4) Initial hot-spring discharge rates.

Since high-resolution temperature profiles and water levels do not directly correspond to TOUGH2 output variables, we converted all temperature $\operatorname{logs}$ to vertically averaged temperatures within reservoir limits, while water levels and temperature logs were used to compute pressures at $-250 \mathrm{~m}$ asl.

We consider two chronological stages in the history of the reservoir. The first one is the socalled "natural state", which spans the long time period before the start of commercial-scale fluid production; at the end of it the system can be considered to be at a quasi-steady state. The second stage corresponds to the exploitation period of the field, when fluid extraction/injection operations significantly perturb the system. This subdivision of the reservoir history greatly simplifies the calibration process of the model.

In the case of the natural state, the calibration is restricted to a relatively small number of estimated parameters since all parameters contributing to the accumulation term in the mass and heat balance equations, such as compressibility, porosity and specific heat, are unimportant under quasi-steady state conditions. The process is also simpler when calibrating the exploitation stage because one can use the parameters from the natural-state calibration as initial estimates, and the calculated temperature and pressure distributions as initial conditions. Such an approach leads to the splitting of observational data into two sets: one for the natural-state model calibration (i.e. initial temperature and pressure profiles, as well as hot springs discharge data), and another for the calibration of the exploitation model (i.e. transient temperatures and pressures in monitoring wells and enthalpies in production wells). Hence, the key properties to be estimated in the Pauzhetsky geothermal field model are as follows (see also Fig. 7 and Table 1):

Parameters determined during the calibration of natural-state data

- Geothermal reservoir (mid-layer) fracture permeability $\left(k_{r}\right.$, in $\left.\mathrm{mD}\right)$

- Mass flow rates at the bottom of the base layer $\left(Q_{b}\right.$, in $\left.\mathrm{kg} / \mathrm{s}\right)$

Parameters determined during the calibration of exploitation data

- Geothermal reservoir (mid-layer) fracture compressibility $\left(C_{r}\right.$, in $\left.\mathrm{Pa}^{-1}\right)$

- Geothermal reservoir (mid-layer) fracture porosity $\left(\phi_{r}\right)$

- Base-layer upflow zone compressibility $\left(C_{b}\right.$, in $\left.\mathrm{Pa}^{-1}\right)$

- Base-layer upflow zone porosity $\left(\phi_{b}\right)$

- Base-layer upflow zone vertical permeability $\left(k_{b}\right.$, in $\left.\mathrm{mD}\right)$

- Upper-layer North site "hydraulic window" permeability $\left(k_{N}\right.$, in $\left.\mathrm{mD}\right)$

- Upper-layer East site "hydraulic window" permeability $\left(k_{E}\right.$, in $\left.\mathrm{mD}\right)$

- Upper-layer West site "hydraulic window" permeability $\left(k_{W}\right.$, in $\left.\mathrm{mD}\right)$. 


\section{Pauzhetsky model calibration}

\subsection{Input data}

Calibration data for the natural-state inverse modeling using iTOUGH2 include 68 points (two natural discharge rates, 14 reservoir pressures at $-250 \mathrm{~m}$ asl, and 52 vertically averaged reservoir temperatures). The different quality of the calibration points was expressed by specifying appropriate standard deviations (i.e. $\sigma_{T}=1-3^{\circ} \mathrm{C} ; \sigma_{P}=0.1-0.5$ bar; $\sigma_{Q}=15-50 \%$ of the measured flow rate).

Calibration data for the 1960-2006 exploitation phase include 58 datasets with timedependent values [enthalpies of the produced fluids (10 data sets), pressures at $-250 \mathrm{~m}$ asl in monitoring wells (22 data sets), and vertically averaged temperatures in monitoring wells (26 data sets)], for a total of 13,675 calibration records. The different quality of the calibration points was expressed by assigning appropriate standard deviations (i.e. $\sigma_{T}=5^{\circ} \mathrm{C}, \sigma_{P}=0.3$ bar, $\sigma_{h}=20$ $\mathrm{kJ} / \mathrm{kg}$ ).

Field exploitation was incorporated in the model by specifying monthly averaged production and injection rates during the January 1960-December 2006 period (Fig. 9).

\subsection{Inverse modeling results}

Results from the inversion revealed that the principal heat and mass transfer processes in the Pauzhetsky geothermal field are controlled by (see also Figs. 6 and 7 and Table 2): (1) the active volume of the geothermal reservoir defined by the geothermal reservoir fracture porosity $\left(\phi_{r}\right)$ and compressibility $\left(C_{r}\right)$, which are responsible for the effective heat and mass capacity within the geothermal reservoir; (2) the upflow from the base layer $\left(Q_{b}\right)$, which is given by the initial natural upflow and the additional upflow caused by the pressure drop during exploitation. The increase in $Q_{b}$ is determined by a group of four parameters, i.e. geothermal reservoir fracture permeability $\left(k_{r}\right)$, base-layer porosity $\left(\phi_{b}\right)$ and base-layer compressibility $\left(C_{b}\right)$, base-layer vertical permeability $\left(k_{b}\right)$; and (3) inflows of cold meteoric waters from above, as defined by permeabilities of the "hydraulic windows" in the upper layer (i.e. $k_{N}, \mathrm{k}_{\mathrm{W}}, k_{E}$ ) and the fracture permeability of the geothermal reservoir itself $\left(k_{r}\right)$. Natural-state inverse modeling indicated that an open lateral boundary is very unlikely. In the model, therefore, the lateral boundaries were assumed to be closed.

The parameters estimated by inverse modeling and residual analysis are summarized in Tables 2 and 3 for both the calibration of the natural state and exploitation periods. Note that the reservoir permeabilities estimated by inverse modeling are consistent with those inferred from semilog analyses of multiwell tests. Moreover, the estimates for the "hydraulic window" permeabilities are within the range expected for alluvial deposits. Standard deviations of residuals were found to be comparable to standard deviations of observational data (Table 3 ).

The plots shown in Fig. 10 reveal that the residuals exhibit some non-random patterns, indicating that there are some systematic modeling errors caused by the coarse discretization and other modeling simplifications. While positive and negative residuals are approximately equally distributed (evidence that no global bias exists), patterns in the pressure and temperature residuals suggest local systematic errors. As a result, the means of the residuals of each data type are somewhat larger than the expected measurement error (see Table 3). Also note that the temperatures in the monitoring wells used for calibration are vertically averaged downhole temperatures; this averaging process is likely to yield some systematic deviations, as reflected in the residual plots.

Inverse modeling of the exploitation phase was executed using the natural-state temperature and pressure distributions (as obtained with the best-fit parameter set) as initial conditions. A linear error analysis indicates that some of the estimated parameters are strongly 
correlated to each other, suggesting that the inverse problem is over-parameterized. To avoid this problem, we removed the compressibilities of the reservoir and base layer from the estimation process and assigned them a fixed value of $2 \times 10^{-6} \mathrm{~Pa}^{-1}$. Moreover, we assigned a value of $5 \mathrm{mD}$ to the base-layer permeability, removing the strong negative correlation of those parameters with porosities.

Following this sequential calibration, we carried out an inversion that integrated both the natural-state and exploitation phases. This analysis confirmed the previous estimates and thus allows for the use of a single set in the natural-state, exploitation, and prediction runs.

\subsection{Heat and mass balances}

Heat and mass balances derived from the model were used to identify the sources for the geothermal reserves in the field. By November 2005, the mass balance for the geothermal reservoir showed that the fluids being produced were contributed by the base-layer upflow $(25.7 \%)$, meteoric inflow through hydraulic windows $(30 \%)$, reservoir fluid storage (fractures $15.3 \%$, matrix $20.7 \%$ ), and injection (8.3\%). Similarly, heat balance indicated the following thermal contributions: base-layer convective heat upflow $(30.8 \%)$, reservoir heat storage (fractures $25 \%$, matrix $38.3 \%$ ), injection (5.1\%), and meteoric water inflow $(0.8 \%)$. These estimates are consistent with the chloride data discussed in Section 2.

\section{Forecast modeling for $2007-2032$}

\subsection{Forecast of exploitation at constant fluid production rate}

The numerical model of the Pauzhetsky geothermal field, as calibrated using exploitation data from the 1960-2006 period, was used to forecast the enthalpy of the produced fluids and reservoir pressures at a specified exploitation load. November 2006 fluid extraction rates (see Table 4) were used for predicting 2007-2032 values.

The deterministic prediction was accompanied by a linear error propagation analysis to estimate the $95 \%$ confidence limits of the computed future values. Figure 11 shows that the enthalpy prediction for production Well 106 in 2032 is in the 692 and $712 \mathrm{~kJ} / \mathrm{kg}$ range. Note that the computed enthalpy values fall outside the $95 \%$ confidence interval during the 1999-2000 period, when the observed enthalpy drops by about $70 \mathrm{~kJ} / \mathrm{kg}$, before it recovers. However, fluid chemistry does not show an erratic behavior, i.e., chloride concentration and $\mathrm{Na} / \mathrm{K}$ geothermometer values decrease gradually. Therefore, we believe that the enthalpy measurements are erroneous, a fact that is not expected to be captured by the uncertainty propagation analysis. Prediction of reservoir pressure in Well 124, located in the central part of the field, shows that the pressure declines to 30.3-31.3 bar by 2033 (Fig. 12). Note that the uncertainty of the model prediction is smaller than that of the input data.

\subsection{Forecast of exploitation at constant wellhead pressures}

We also predicted the exploitation of the Pauzhetsky geothermal field assuming that the two-phase wells were assumed to be produced under constant wellhead pressure conditions. The coupled wellbore-reservoir simulator implemented in TOUGH2 was used to model the 20072032 exploitation scenario. Production flow rates were calculated according to the following wellbore-reservoir equation:

$$
Q=P I \cdot \sum_{\beta} \frac{k_{r \beta} \rho_{B H \beta}}{\mu_{B H \beta}}\left(P_{r}-P_{B H}\right)
$$

where $Q[\mathrm{~kg} / \mathrm{s}]$ is the well fluid flow rate, $k_{r}$ is the relative permeability, $\rho_{B H}\left[\mathrm{~kg} / \mathrm{m}^{3}\right]$ is the bottomhole fluid density, $\mu_{B H}[\mathrm{~Pa} \cdot \mathrm{s}]$ is the bottomhole fluid viscosity, $P_{r}[\mathrm{~Pa}]$ is the geothermal reservoir pressure (i.e. the pressure in the model element that contains the wellbore), $P_{B H}[\mathrm{~Pa}]$ is the bottomhole pressure at $-250 \mathrm{~m}$ asl, which is a function of fluid flow rate and the flowing enthalpy of the two-phase mixture. The subscript $\beta$ refers to the two phases (liquid; gas). 
Exploitation Wells 103, 106, 108, 120, 121, 122, 123, GK3, and 131 were assigned the wellhead pressures (WHP) given in Table 4. Bottomhole pressures were calculated for each well using the $\mathrm{HOLA}^{3}$ wellbore simulator (Aunzo et al., 1991) and by taking into consideration the specific design of each of the wells. The productivity indices $(P I)$ of wells were estimated directly by the model, based on current production rates (Table 4). While the PIs were assumed to be constant, the effects of boiling are accounted for through the relative permeability, viscosity, density, and enthalpy terms in Eq. (2).

Figure 13 shows how $P_{B H}$ in Well 123 changes as a function of fluid enthalpy and flow rate. For example, for the production data in October 2006 (indicated by the star in Fig. 13), a bottomhole pressure of approximately 27 bar is calculated. Since the reservoir pressure at that time was 30.8 bar (indicated by the thick contour line), the reservoir conditions were sufficient to sustain fluid production in this well. If the production rate or enthalpy changes such that the star is below the contour line corresponding to the prevailing reservoir pressure, then this two-phase production well must be taken off-line, as there will not be sufficient pressure support to keep the well under production.

The initial conditions set for predicting the 2007-2032 period correspond to previously calculated modeling scenarios. The model indicated that five additional make-up wells were necessary to sustain the production level: Well 120A (to be turned on in 2008), 123A (2012), 107A (2015), 102A (2025), 102B (2028). Simulations were run to determine the optimal locations of the make-up wells (see Fig. 8) needed to sustain the assumed total production rate. These wells had a typical Pauzhetsky exploitation well design; i.e. $219 \mathrm{~mm}$ diameter to a depth of $250 \mathrm{~m}$ and $190 \mathrm{~mm}$ below. The WHP is assumed to be 4 bar, with a separation pressure of 2.84 bar. The PIs of the added wells were estimated based on the assumption of an initial production rate of $30 \mathrm{~kg} / \mathrm{s}$. To maintain a minimum well production rate of $10 \mathrm{~kg} / \mathrm{s}$, it was necessary to set the WHP at 3.0 bar in Well 131 in 2020, and at 3.5 bar in Well 122 in 2028. Figures 14 and 15 show predictions of total two-phase and steam production rates for the 20072032 period. The total discharge and steam production rates are maintained at $266.1-317.7 \mathrm{~kg} / \mathrm{s}$ $(288.3 \mathrm{~kg} / \mathrm{s}$ on average), and $26.8-31.9 \mathrm{~kg} / \mathrm{s}(28.9 \mathrm{~kg} / \mathrm{s}$ on average), respectively. The minimum production from the existing wells $(103,106,108,120,121,122,123,131$, and GK3) is 159.2 $\mathrm{kg} / \mathrm{s}$ (including $12.8 \mathrm{~kg} / \mathrm{s}$ of steam).

\footnotetext{
${ }^{3}$ HOLA is a multi-feedzone geothermal wellbore simulator for pure water, which can handle both single- and two-phase flows in vertical and inclined pipes and calculate the flowing temperature, pressure, and enthalpy profiles in the well for given discharge conditions. The simulator solves numerically the differential equations that describe the steady-state energy, mass and momentum for flow in the wellbore.
} 


\section{Conclusions}

The TOUGH2 forward and iTOUGH2 inverse modeling codes were used to calibrate a model of the Pauzhetsky geothermal field based on natural-state and 1960-2006 exploitation data. We identified and estimated key model parameters, i.e. geothermal reservoir fracture porosity, initial natural upflow, base-layer porosity and the permeabilities of the hydraulic windows in the upper layer of the model.

The computed heat and mass balances helped to identify the sources for the geothermal reserves in the field. The largest contribution comes from fluids stored in the reservoir, followed by meteoric water recharge, base-layer upflow, and injection waters.

Model predictions for the period 2007-2032 show the possibility of maintaining steam production at an average rate on the order of $30 \mathrm{~kg} / \mathrm{s}$ (total flow rate about $290 \mathrm{~kg} / \mathrm{s}$ ), provided that five additional make-up wells are put into operation, and that the steam transmission lines from Wells 122 and 131 are improved to allow a reduction in wellhead pressures. This rate of steam production would be sufficient to support an average electricity generation of $7 \mathrm{MWe}$ at the Pauzhetsky power plant.

The calibrated model can be used for estimating overall reservoir behavior under future production scenarios. Nevertheless, to make reliable predictions of enthalpy and pressure declines, and to better match individual well data, the model should be improved by refining the model structure, increasing grid resolution, and capturing more accurately the cooling phenomena occurring in the geothermal system. We plan to develop such a model in the future since it likely will have improved predictive capabilities for scenarios that deviate more strongly from the current reservoir conditions.

\section{Acknowledgment}

We very much appreciate the constructive comments made by the anonymous reviewers. Valuable help from Karsten Pruess (LBNL) is highly appreciated. We are grateful to Pat Dobson and Dan Hawkes for their careful reviews of the manuscript. This work was supported by SUE "Kamchatskburgeotermia", FEB RAS project 06-I-OH3-109 and RFBR project 06-05-64688a, and in part by the U.S. Dept. of Energy under Contract No. DE-AC02-05CH11231. 


\section{References}

Aunzo Z.P., Bjornsson G., Bodvarsson G.S, 1991. Wellbore models GWELL, GWNACL and HOLA. Users Guide. Lawrence Berkeley National Laboratory report LBNL-31428, Berkeley, CA, USA, 102 pp.

Finsterle, S., 2004. Multiphase inverse modeling: Review and iTOUGH2 applications. Vadose Zone J. 3, 747-762.

Haukwa, C.B., 1998. AMESH - A mesh creating program for the integral finite difference method: A User's Manual. Lawrence Berkeley National Laboratory report LBNL-45284, Berkeley, CA, USA, 53 pp.

Kiryukhin, A.V., Sugrobov, V.M., 1987. Heat and mass transfer in geothermal systems of Kamchatka. Nauka, Moscow, Russia, 149 pp. (in Russian).

Kiryukhin, A.V., Yampolsky, V.A., 2004. Modeling study of the Pauzhetsky geothermal field, Kamchatka, Russia. Geothermics 33, 421-442.

Kiryukhin, A.V., Asaulova, N.P., Rychkova, T.V., Obora, N.V., 2006. Modeling the Pauzhetsky geothermal field, Kamchatka, Russia. Geothermal Resources Council Transactions 30, 819825 .

Korobov, A.D., Goncharenko, O.P., Rikhter, Y.A., Molostovsky, E.A., 1989. Petrographical and mineralo-geochemical characteristics of the geothermal alteration in Pauzhetsky geothermal field (South Kamchatka). Report to Institute of Volcanology, Petropavlovsk-Kamchatsky, Russia, 379 pp. (In Russian)

Ladygin, V., Frolova, J., Rychagov, S., 2000. Formation of composition and petrophysical properties of geothermally altered rocks in a geothermal reservoir. In: Proceedings of World Geothermal Congress 2000, Japan, pp. 2695-2699.

Piip, B.I. (ed.), 1965. Pauzhetka Hot Springs in Kamchatka. Nauka, Moscow, Russia, 207 pp. (In Russian)

Pruess, K., Narasimhan, T.N., 1985. A practical method for modeling fluid and heat flow in fractured porous media. Society of Petroleum Engineers Journal 25, 14-26.

Pruess, K., Oldenburg, C., Moridis, G., 1999. TOUGH2 User's Guide, Version 2.0. Lawrence Berkeley National Laboratory report LBNL-43134, Berkeley, CA, USA, 198 pp.

Sugrobov, V.M., 1970. Evaluation of operational reserves of high-temperature waters. Geothermics, Special Issue 2, 1256-1260.

Yanovsky, F.A., 1989. Heat conductivity of the volcanogenic-sedimentary rocks of Kamchatka, Volcanology and Seismology Journal 5, 77-84. 


\section{Table 1}

Pauzhetsky geothermal field modeling study. Model parameters

(Shown in regular font: key TOUGH2 input parameters; shown in bold font: parameters to be estimated using iTOUGH2)

\begin{tabular}{|c|c|}
\hline Parameter & Value \\
\hline \multicolumn{2}{|c|}{ Geothermal reservoir (mid-layer) fractures sub-domain "fracl" } \\
\hline Rock density (fractures), $\mathrm{kg} / \mathrm{m}^{3}$ & 2000 \\
\hline Porosity (fractures) & (to be estimated) \\
\hline Permeability (fractures), mD & (to be estimated) \\
\hline Heat conductivity, $\mathrm{W} / \mathrm{m}^{\circ} \mathrm{C}$ & 1.8 \\
\hline Specific Heat, $\mathrm{J} / \mathrm{kg}^{\circ} \mathrm{C}$ & 1000 \\
\hline Compressibility & (to be estimated) \\
\hline \multicolumn{2}{|c|}{ Geothermal reservoir (mid-layer) matrix sub-domain "matr1" } \\
\hline Rock density (matrix), $\mathrm{kg} / \mathrm{m}^{3}$ & 2000 \\
\hline Porosity (matrix) & 0.2 \\
\hline Permeability (matrix), $\mathrm{mD}$ & 0.01 \\
\hline Heat conductivity, $\mathrm{W} / \mathrm{m}^{\circ} \mathrm{C}$ & 1.8 \\
\hline Specific Heat, $\mathrm{J} / \mathrm{kg}^{\circ} \mathrm{C}$ & 1000 \\
\hline Compressibility, $\mathrm{Pa}^{-1}$ & $2.0 \times 10^{-6}$ \\
\hline \multicolumn{2}{|c|}{ Base Layer (upflow zone) } \\
\hline Rock density, $\mathrm{kg} / \mathrm{m}^{3}$ & 2800 \\
\hline Porosity & (to be estimated) \\
\hline Permeability, mD & (to be estimated) \\
\hline Heat conductivity, $\mathrm{W} / \mathrm{m}^{\circ} \mathrm{C}$ & 2.1 \\
\hline Specific Heat, $\mathrm{J} / \mathrm{kg}^{\circ} \mathrm{C}$ & 1000 \\
\hline Compressibility, $\mathbf{P a}^{-1}$ & (to be estimated) \\
\hline \multicolumn{2}{|c|}{ Sources assigned in base-layer domain "BASE2" sub-domain "C1" } \\
\hline Mass flow rate, $\mathrm{kg} / \mathrm{s}$ & (to be estimated) \\
\hline Enthalpy, $\mathrm{kJ} / \mathrm{kg}$ & 950 \\
\hline \multicolumn{2}{|c|}{ Upper Layer } \\
\hline Permeability (North inflow zone), mD & (to be estimated) \\
\hline Permeability (East inflow zone), mD & (to be estimated) \\
\hline Permeability (West inflow zone), mD & (to be estimated) \\
\hline Permeability (impermeable caprock), $\mathrm{mD}$ & 0.0001 \\
\hline
\end{tabular}


Table 2

iTOUGH2 parameters estimates and their uncertainties

\begin{tabular}{|l|l|c|c|}
\hline Group * & Estimated Parameter & Value & 95\% Confidence Interval \\
\hline \multirow{3}{*}{1} & $\mathrm{k}_{\mathrm{r}}, \mathrm{mD}$ & 83 & $76-93$ \\
\cline { 2 - 4 } & $\mathrm{C}_{\mathrm{r}}, \mathrm{Pa}^{-1}$ & $2.010^{-6}$ & (fixed) \\
\cline { 2 - 4 } & $\phi_{\mathrm{r}}$ & 0.094 & $0.090-0.098$ \\
\hline \multirow{3}{*}{2} & $\mathrm{Q}_{\mathrm{b}}, \mathrm{kg} / \mathrm{s}$ & 44.2 & $39.7-48.7$ \\
\cline { 2 - 4 } & $\mathrm{C}_{\mathrm{b}}, \mathrm{Pa}^{-1}$ & $2.010^{-6}$ & (fixed) \\
\cline { 2 - 4 } & $\phi_{\mathrm{b}}$ & 0.045 & $0.037-0.053$ \\
\cline { 2 - 4 } & $\mathrm{k}_{\mathrm{b}}, \mathrm{mD}$ & 5 & (fixed) \\
\hline \multirow{3}{*}{3} & $\mathrm{k}_{\mathrm{N}}, \mathrm{mD}$ & 145 & $129-162$ \\
\cline { 2 - 4 } & $\mathrm{k}_{\mathrm{E}}, \mathrm{mD}$ & 11 & $10-12$ \\
\cline { 2 - 4 } & $\mathrm{k}_{\mathrm{W}}, \mathrm{mD}$ & 490 & $371-645$ \\
\hline
\end{tabular}

* Parameters affecting mainly: heat and mass capacity of the geothermal reservoir (Group 1); base-layer upflow (Group 2); cold meteoric water inflows from above (Group 3).

Table 3

Summary of the iTOUGH2 inverse modeling residual analysis

\begin{tabular}{|l|l|l|}
\hline \multicolumn{1}{|c|}{ Observational data } & \multicolumn{1}{|c|}{$\begin{array}{c}\text { Standard deviations of } \\
\text { observational data }\end{array}$} & Standard deviations of residuals \\
\hline \multicolumn{1}{|c|}{ Natural State } \\
\hline Pressure (at -250 m asl) & $0.1-0.5$ bar & $0.5 \mathrm{bar}$ \\
\hline Temperature (vertically averaged) & $1-3^{\circ} \mathrm{C}$ & $7.5^{\circ} \mathrm{C}$ \\
\hline Hot springs flow rate & $15 \% \quad 6 \%$ \\
\hline \multicolumn{1}{|c|}{ Exploitation } \\
\hline Enthalpy of produced fluids & $20 \mathrm{~kJ} / \mathrm{kg}$ & $36 \mathrm{~kJ} / \mathrm{kg}$ \\
\hline Pressure (at -250 m asl) & $0.3 \mathrm{bar}$ & $0.4 \mathrm{bar}$ \\
\hline Temperature (vertically averaged) & $5^{\circ} \mathrm{C}$ & $12^{\circ} \mathrm{C}$ \\
\hline
\end{tabular}


Table 4

Characteristics of Pauzhetsky exploitation and injection wells (as of November 2006)

\begin{tabular}{|c|c|c|c|c|c|c|}
\hline Well & $\begin{array}{l}\text { Flow } \\
\text { rate } \\
(\mathrm{kg} / \mathrm{s})\end{array}$ & $\begin{array}{l}\text { Enthalpy * } \\
(\mathrm{kJ} / \mathrm{kg})\end{array}$ & $\begin{array}{c}\text { Separation } \\
\text { pressure } \\
\text { (bar) }\end{array}$ & $\begin{array}{l}\text { WHP } \\
\text { (bar) }\end{array}$ & $\begin{array}{l}\text { Steam rate * } \\
(\mathrm{kg} / \mathrm{s})\end{array}$ & $\begin{array}{c}\mathrm{PI} * \\
\left(10^{-12} \mathrm{~m}^{3}\right)\end{array}$ \\
\hline \multicolumn{7}{|c|}{ Production wells } \\
\hline 103 & 23.9 & 793.0 & 3.24 & 5.98 & 2.9 & 8.00 \\
\hline 106 & 32 & 750.0 & 2.35 & 3.14 & 2.9 & 10.20 \\
\hline 108 & 24.6 & 746.0 & 2.35 & 2.75 & 2.3 & 3.02 \\
\hline 120 & 18.8 & 818.0 & 3.24 & 4.61 & 1.9 & 1.48 \\
\hline 121 & 21.2 & 814.0 & 3.24 & 3.43 & 2.4 & 1.48 \\
\hline 122 & 43.8 & 786.0 & 3.14 & 4.61 & 5.0 & 43.00 \\
\hline 123 & 46.8 & 808.0 & 3.24 & 3.83 & 4.3 & 18.50 \\
\hline GK3 & 29.2 & 785.0 & 2.45 & 2.55 & 3.9 & 11.00 \\
\hline 131 & 34.6 & 805.0 & 2.55 & 5.49 & 4.3 & 4.20 \\
\hline \multicolumn{7}{|c|}{ Injection well } \\
\hline 142 & $18.0^{\#}$ & & & & & \\
\hline \multicolumn{7}{|c|}{$\begin{array}{l}\text { WHP: Wellhead pressure; PI: Productivity index } \\
\text { * Enthalpies, steam rates, and production indices are derived from the model } \\
\text { \# Injection rate is relatively small as most of the separated fluid is discharged into the Pauzhetsky } \\
\text { River. }\end{array}$} \\
\hline
\end{tabular}




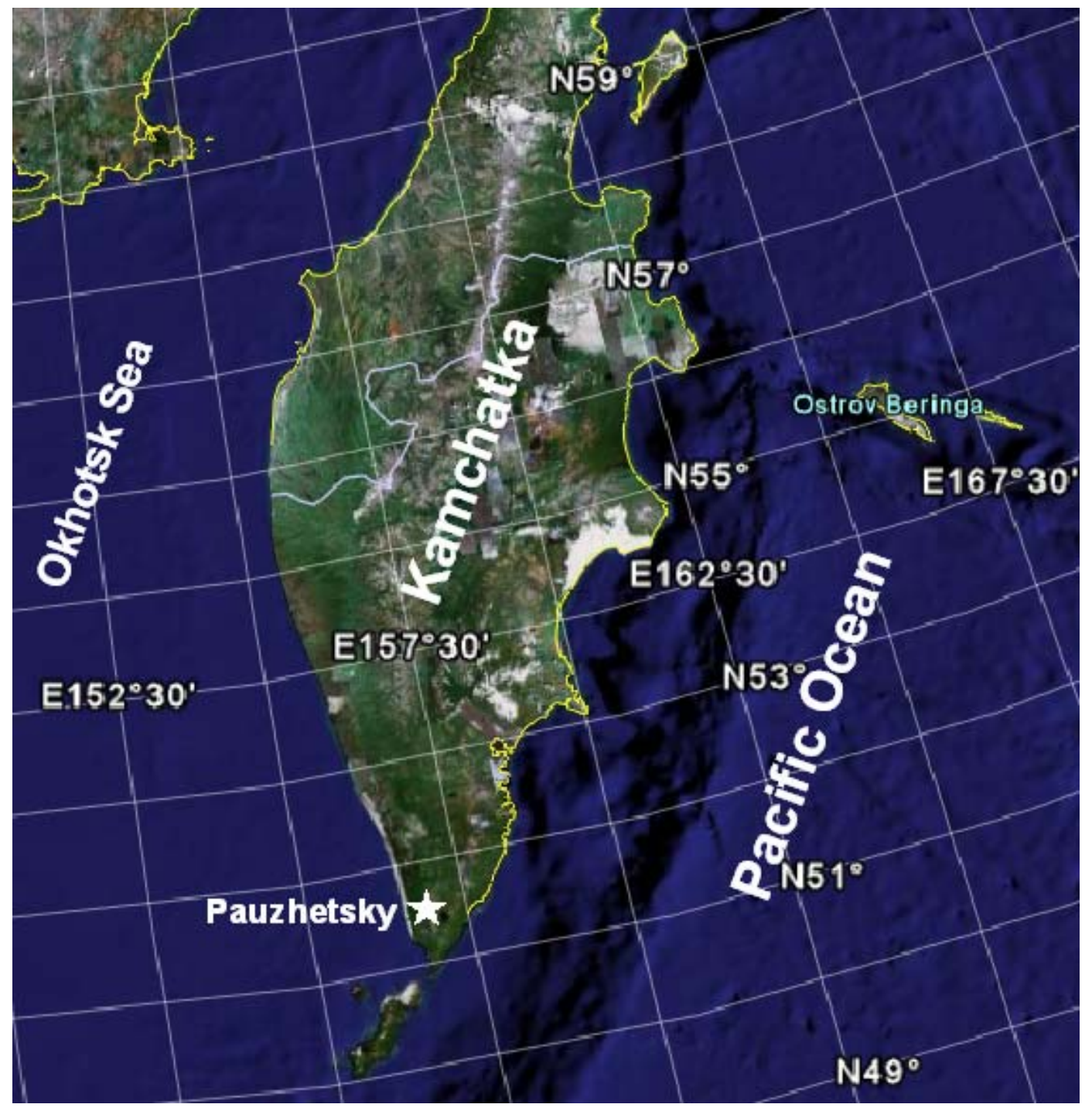

Fig. 1 Location of the Pauzhetsky geothermal field on the Kamchatka Peninsula. 


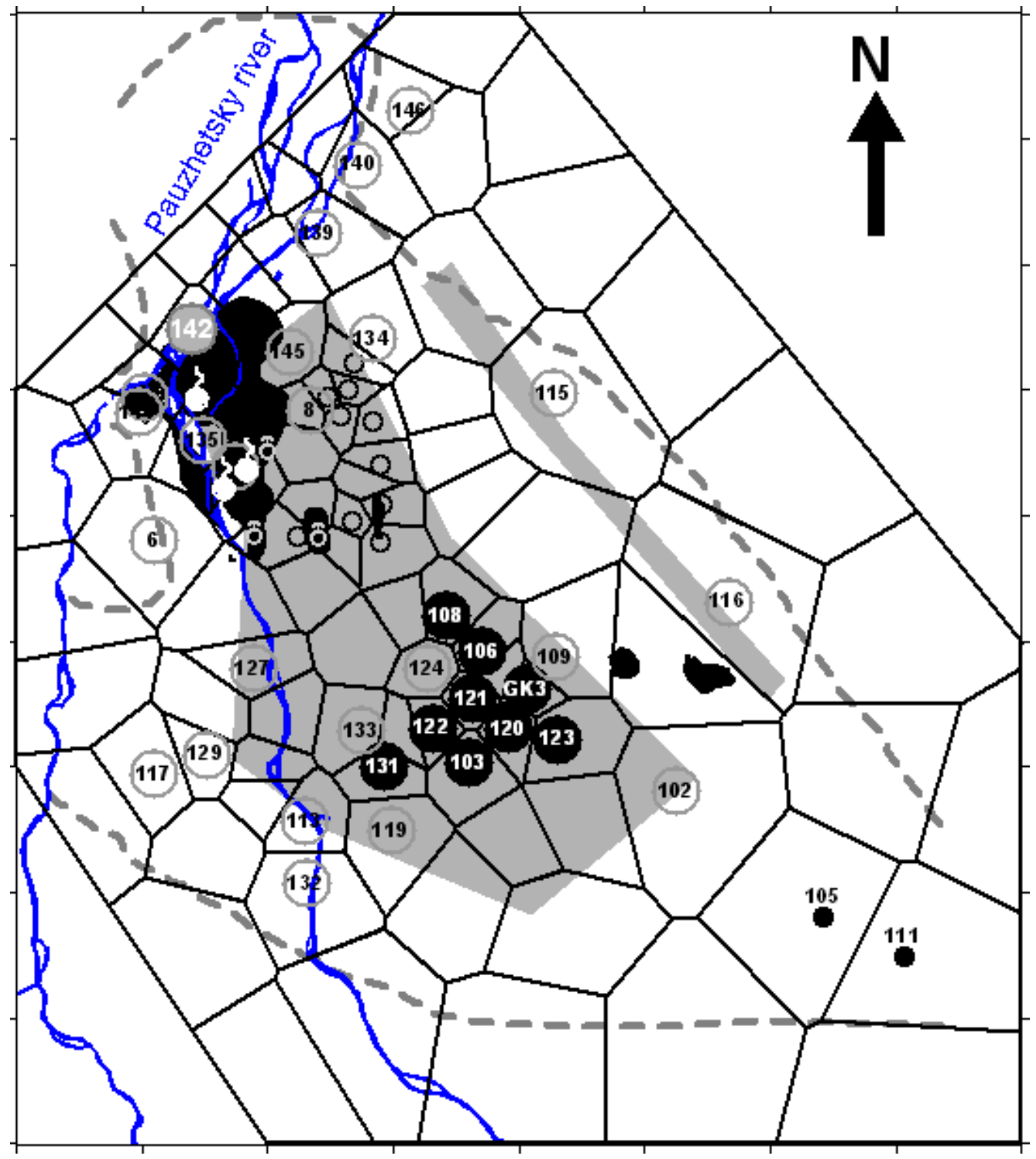

Fig. 2 Pauzhetsky wellfield and plan view of the computational mesh used in the study. Black filled circles with numbers inside - existing exploitation wells; small open circles - old exploitation wells; open circles with numbers inside - pressure and temperature monitoring wells; filled grey circle with number inside - wells used for injection; black filled circles with numbers outside - exploration wells in south-east site. This map shows main hot springs (white symbols), steam jets (black symbols) inside of the thermal areas with temperature above $20^{\circ} \mathrm{C}$ at $1 \mathrm{~m}$ depth (shown as a black areas). Dashed line with gray area inside are contours of high geoelectrical conductivity, associated with upflow zone. Axes grid scale is $500 \mathrm{~m}$. 


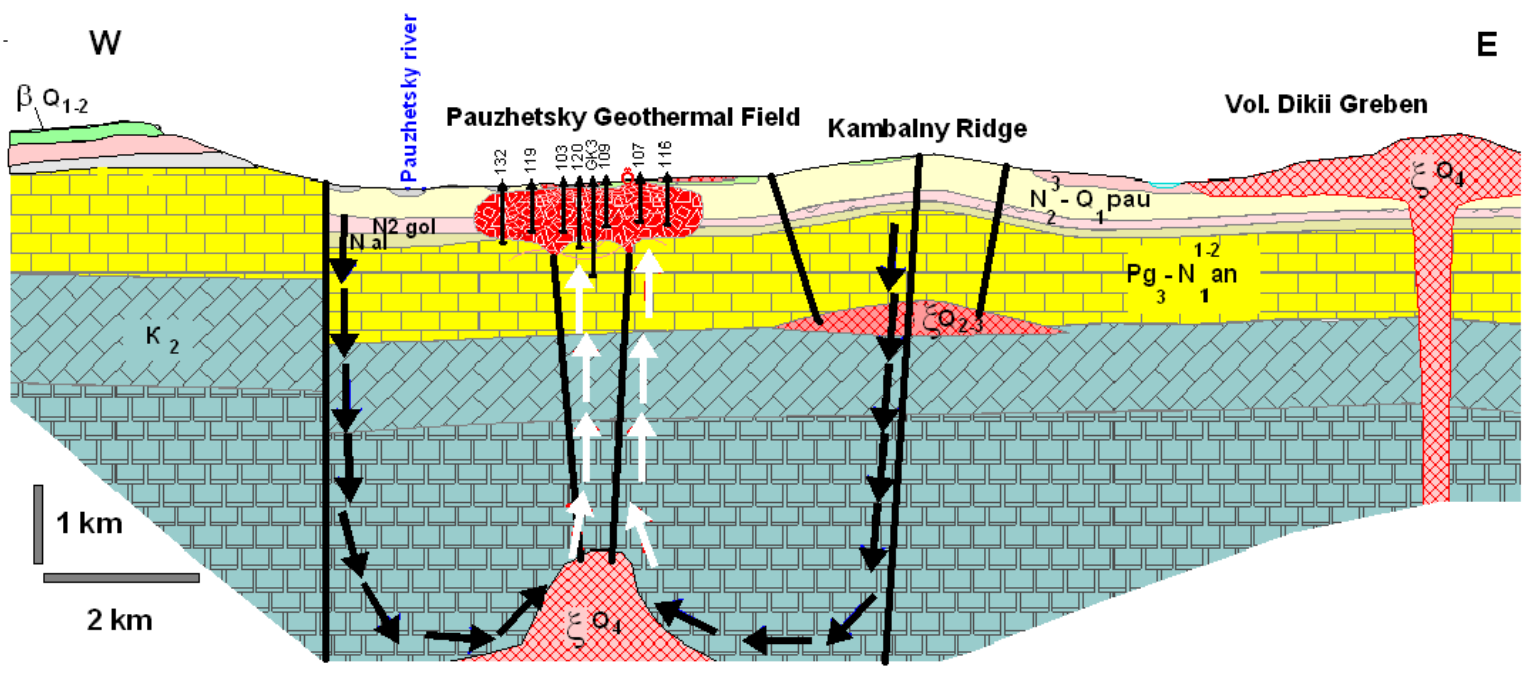

Fig. 3 Conceptual hydrogeological model of the Pauzhetsky hydrothermal system. Lithologic units: $\mathrm{K}_{2}$ - metamorphic basement, $\mathrm{Pg}_{3}-\mathrm{N}_{1}{ }^{1-2}$ an - Miocene sandstones, $\mathrm{N}$ al - Neogene andesite tuffs and lavas, $\mathrm{N}_{2}$ gol -Golyginsky Layer, $\mathrm{N}_{2}{ }^{3}-\mathrm{Q}_{1}$ pau - Pauzhetka tuff formation, $\beta \mathrm{Q}_{1-2}$-andesites, $\xi \mathrm{Q}_{2-3}, \xi \mathrm{Q}_{4}$ - dacite extrusive complex. Black arrows: recharge; white arrows: discharge; black lines: faults; short vertical black lines: geothermal wells. 


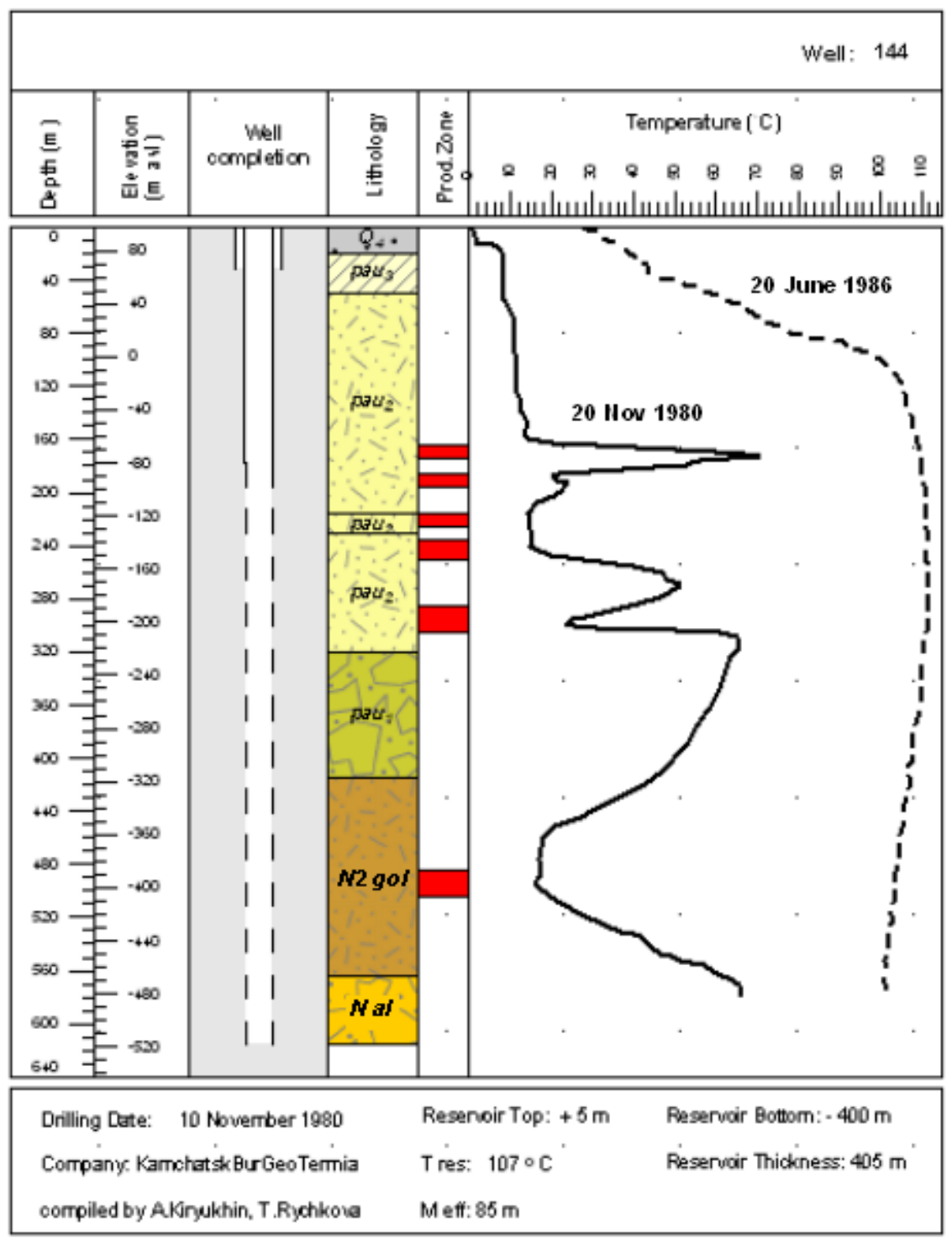

Fig. 4. Downhole logs for Pauzhetsky Well 144 indicating the double-porosity characteristics of the hydrothermal reservoir. Shown are the lithological column, production zones, and temperature logs recorded during cold-water injection (November 20, 1980) and after thermal recovery (June 18, 1982). The log obtained during injection clearly indicates the location of fracture zones bellow the cased part of the well. Denotes $\mathrm{pau}_{1}, \mathrm{pau}_{2}, \mathrm{pau}_{3}-$ marked subunits of the $\mathrm{N}_{2}{ }^{3}-\mathrm{Q}_{1}$ pau - Pauzhetka tuff formation. 


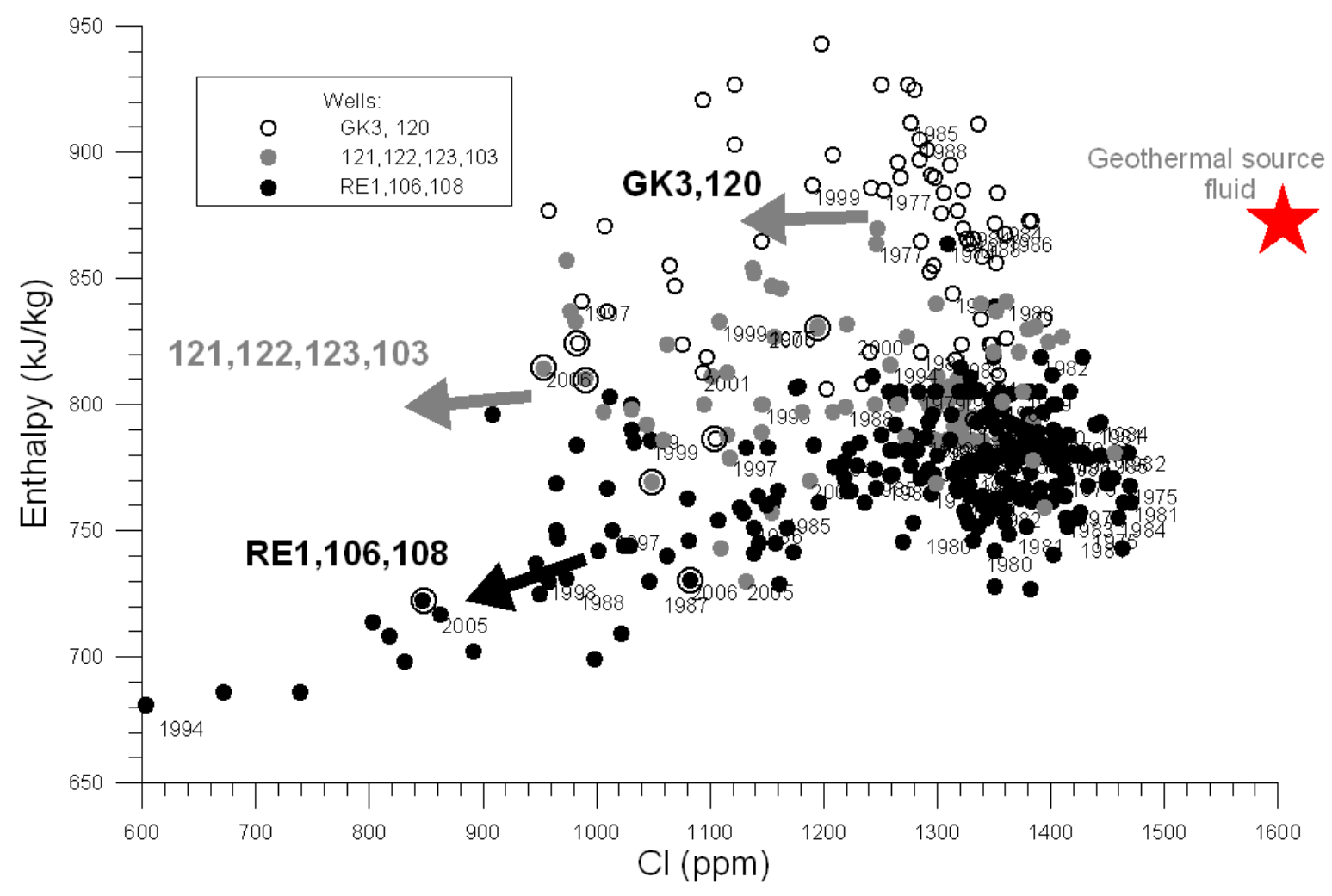

Fig. 5. Enthalpy-chloride diagram for fluids produced by Pauzhetsky geothermal wells. The arrows indicate how fluid characteristics change with time for three groups of wells. Numbers indicate year of production; double circles: 2006 data 


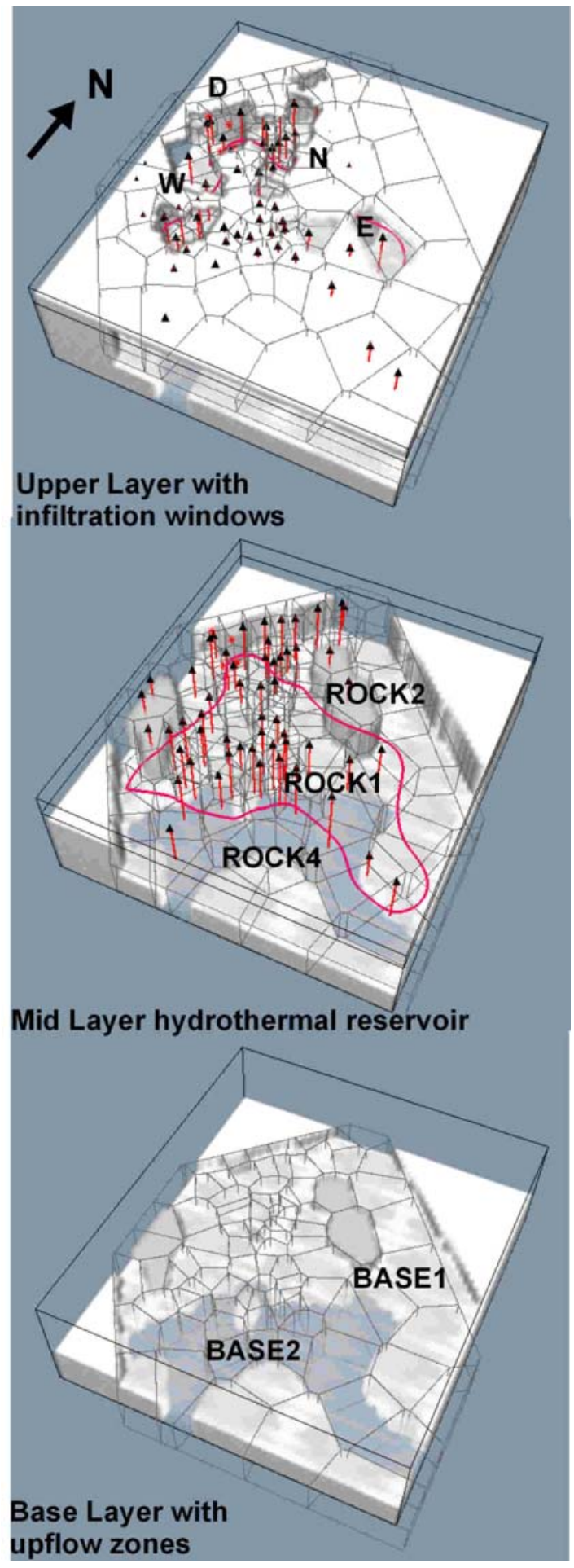

Fig. 6. Three-layer structure of the conceptual hydrogeological model of the Pauzhetsky field and corresponding computational grid (the area of the surface mesh is $13.6 \mathrm{~km}^{2}$; the model has a vertical thickness of $1.25 \mathrm{~km}$ ); more transparent domains correspond to higher permeabilities. Upper Layer zonation: D-hot springs natural discharge domain; N, E, W-north, east and west meteoric water infiltration windows. Mid Layer zonation: ROCK1, 2, 4-domains with different permeabilities. Base Layer zonation: BASE2-upflow zone, BASE1-host rocks (see text for details) 

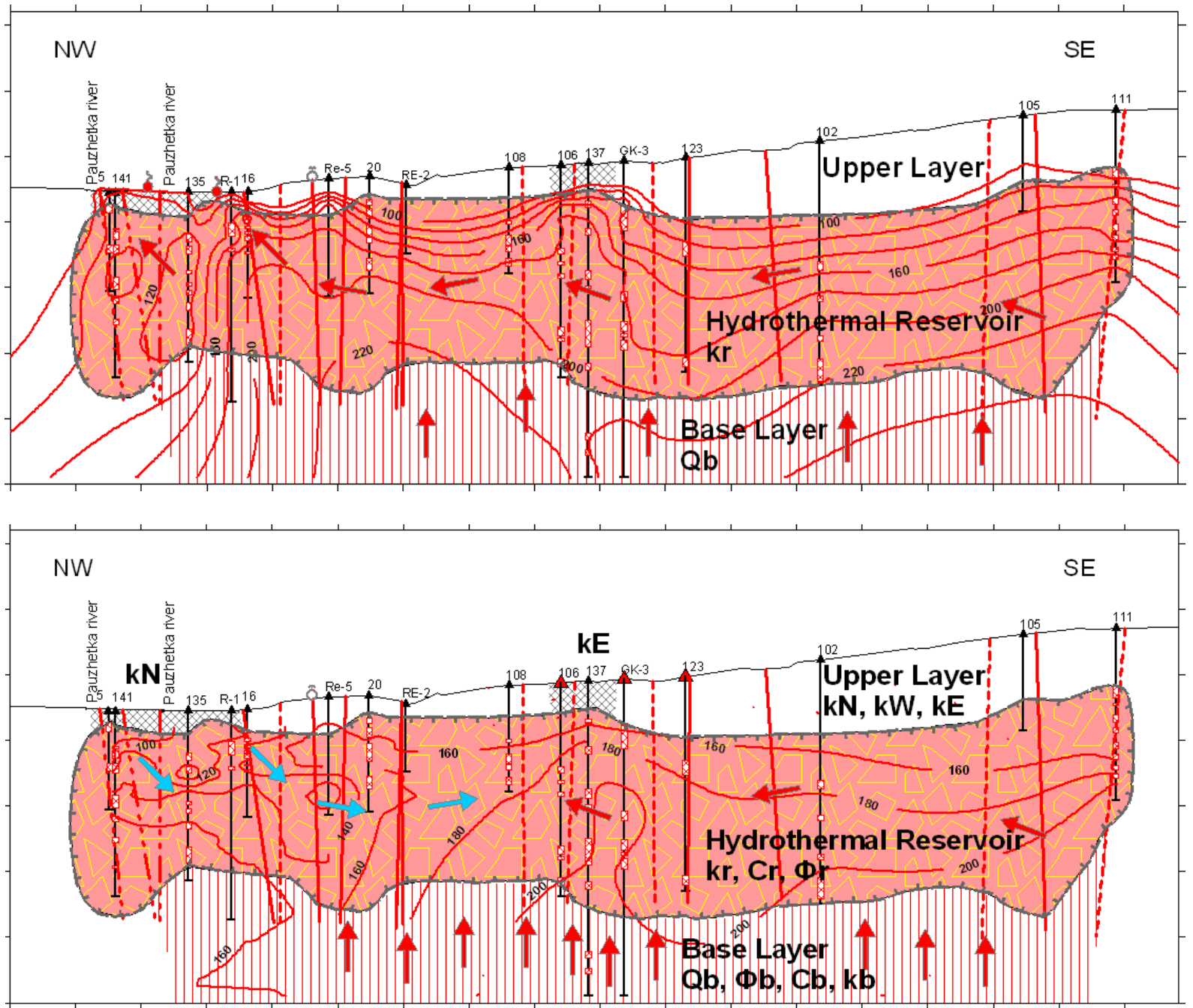

Fig. 7. Conceptual hydrogeological model of the Pauzhetsky geothermal field and paramterization of corresponding numerical model: natural state (above) and exploitation (below). Isotherms have been interpolated from measured data; the upper panel shows 1974 data, representing "before exploitation" conditions; the lower panel shows 1989 data, representing "during exploitation" conditions. Tick marks on the axes are placed $250 \mathrm{~m}$ apart. Arrows indicate streamlines; hatched area represent the boundaries of hydrothermal reservoir; crossed areas show the infiltration windows; vertical lines originating at triangles are wells; sub vertical lines are faults (continuous confirmed, dashed - assumed); $\mathrm{k}_{\mathrm{N}}, \mathrm{k}_{\mathrm{W}}, \mathrm{k}_{\mathrm{E}}, \mathrm{k}_{\mathrm{r}}, \mathrm{C}_{\mathrm{r}}, \Phi_{\mathrm{r}}, \mathrm{Q}_{\mathrm{b}}, \Phi_{\mathrm{b}}, \mathrm{C}_{\mathrm{b}}, \mathrm{k}_{\mathrm{b}}$ are the model parameters to be estimated (see text and Table 2 for details). 


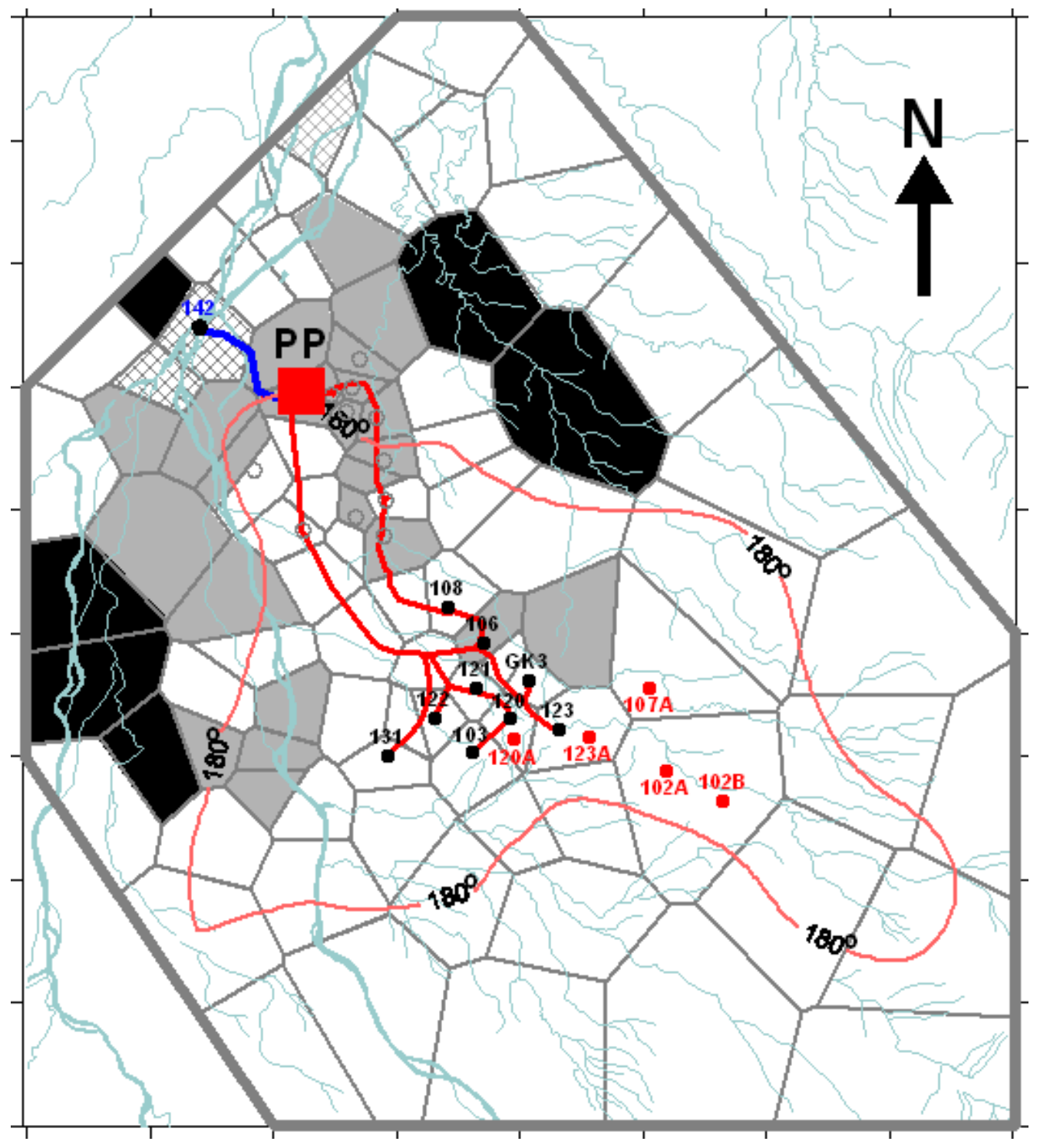

Fig. 8. Schematic map of the Pauzhetsky geothermal field. Polygons indicate the numerical grid; existing wells are shown as black circles, additional wells are indicated by crossed circles; Well 142 is the injector; the $180^{\circ} \mathrm{C}$ contour line corresponds to the initial temperature at $-250 \mathrm{~m}$ asl; elements representing low-permeability domains in the hydrothermal reservoir are in black; cross-hatched areas indicate hot springs discharge zones in the upper layer before exploitation; gray areas represent meteoric water inflow zones; open circles show abundant old producing wells; PP represents the Pauzhetsky power plant; thick lines are steam transmission lines. Distances along the axes are given in meters. Tick marks on the axes are placed $500 \mathrm{~m}$ apart. 

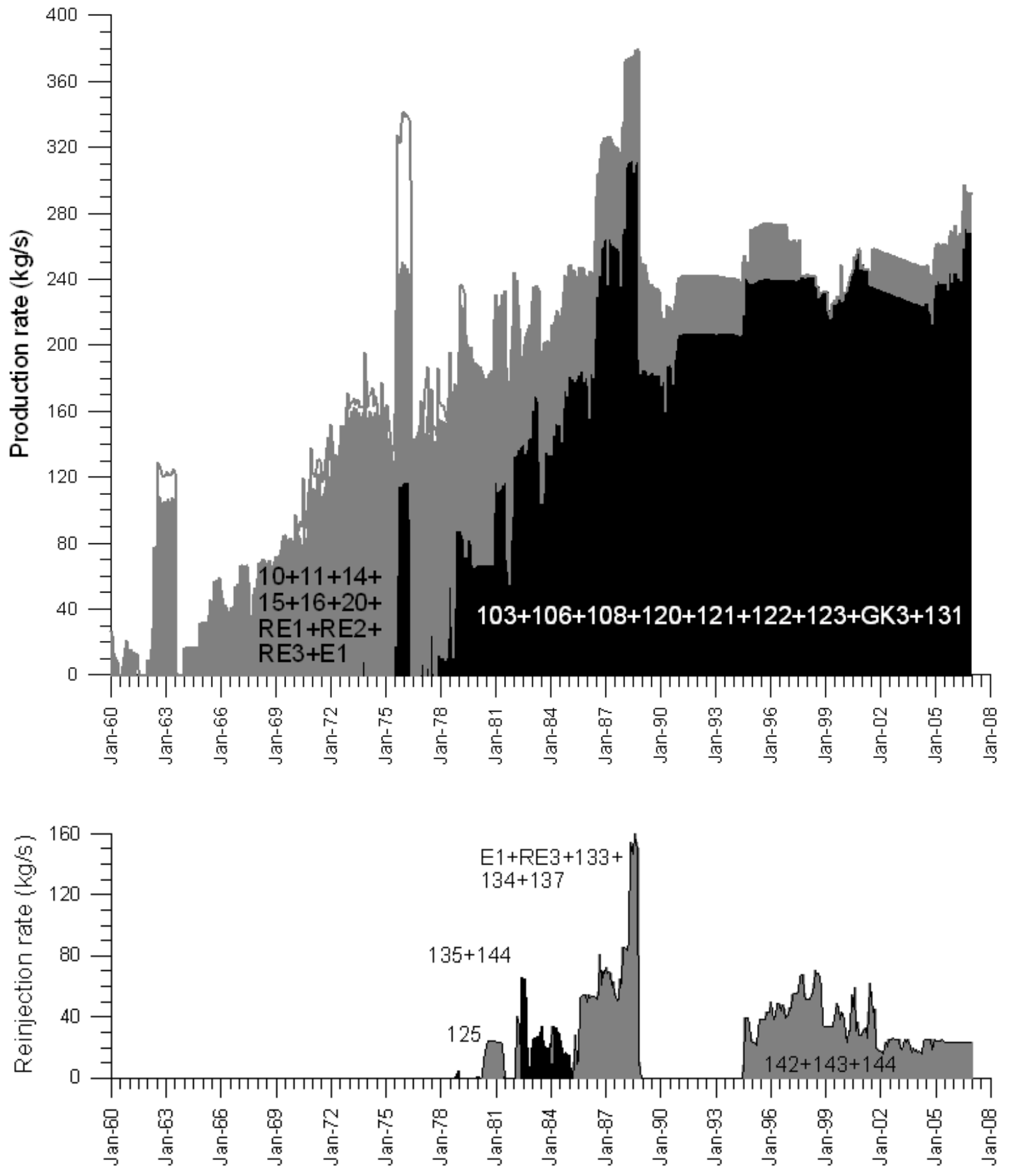

Fig. 9. Pauzhetsky geothermal field during the 1996-2006 exploitation period. Top panel: Total mass production rates; data on Old North Site production wells shown in grey; data on existing production wells shown in black. Bottom panel: injection rates; cold-water injection shown in black; $100-120^{\circ} \mathrm{C}$ injection in gray. 

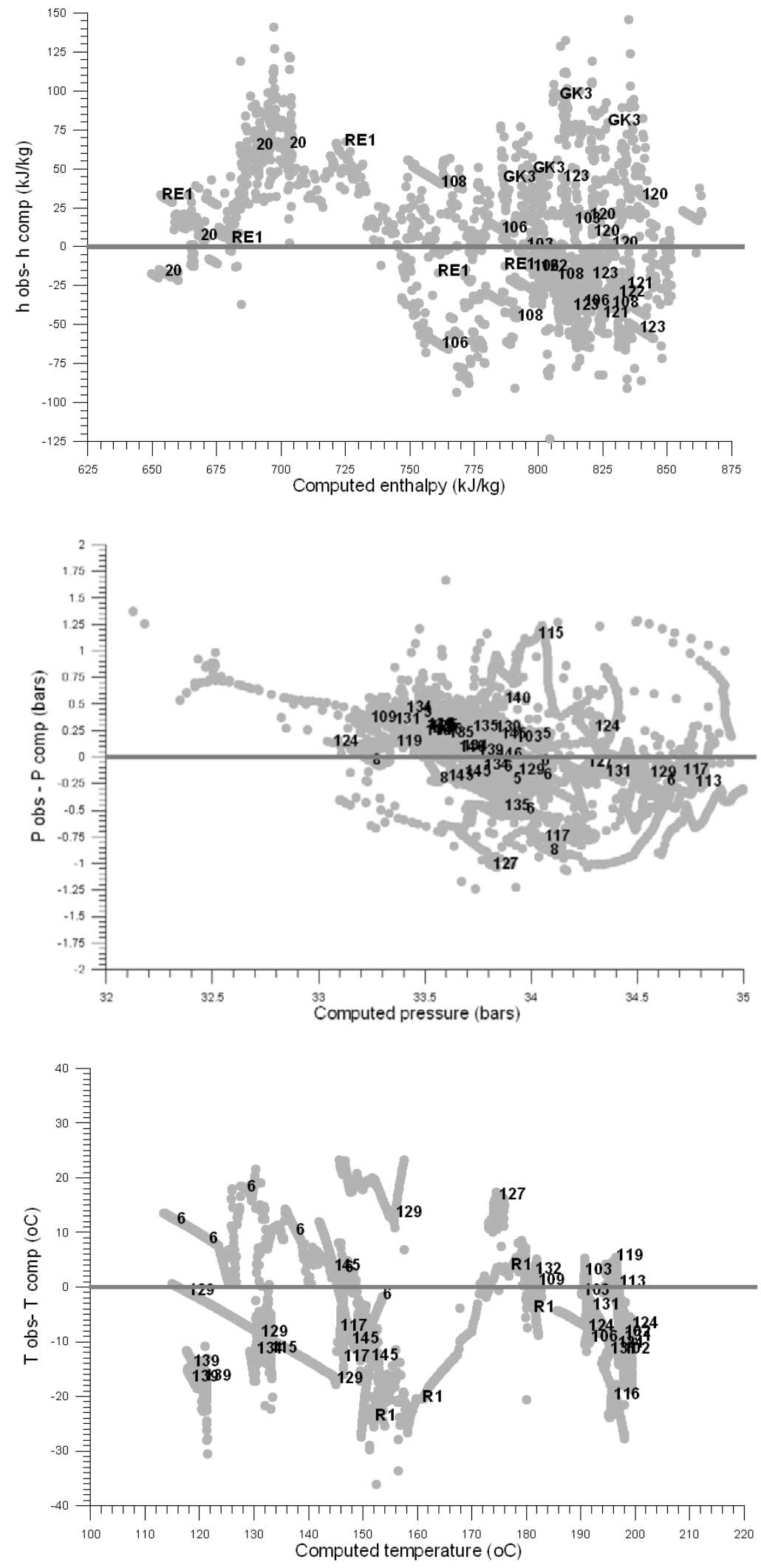

Fig. 10. Residual plots for enthalpy (top panel), pressure (middle panel), and temperature (bottom panel). Residuals are defined as the differences between observed and computed data. Numbers correspond to calibration point numbers. 


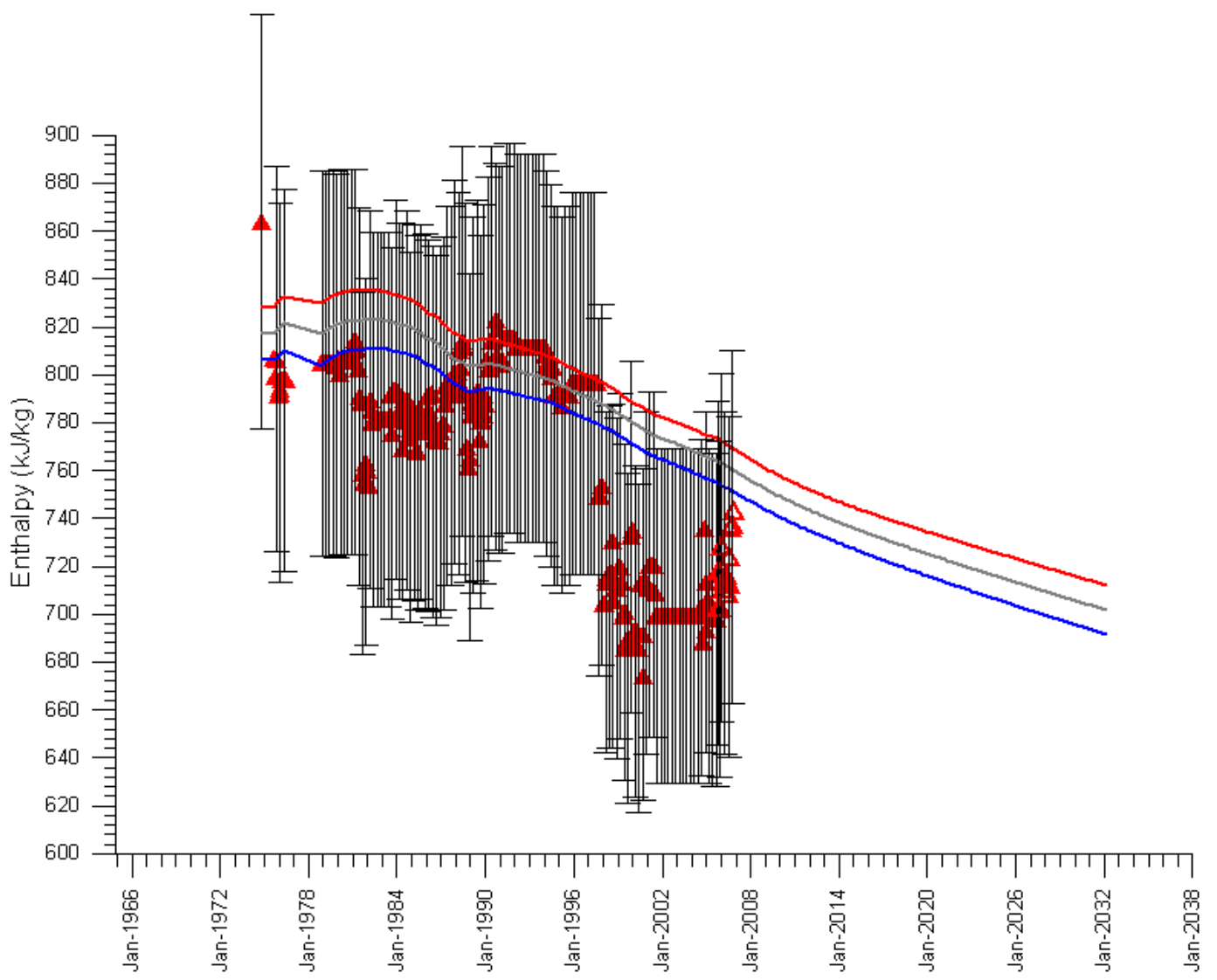

Fig. 11. Prediction and linear uncertainty propagation analysis for the Pauzhetsky model as applied to Well \#106 enthalpy data. Lines: computed mean and 95\% confidence interval; solid triangles: observed data; open triangles: 2006 data taken with repaired sensors. Bars represent the 95\% confidence intervals for enthalpy data, assuming a standard deviation of $\sigma=20 \mathrm{~kJ} / \mathrm{kg}$. 


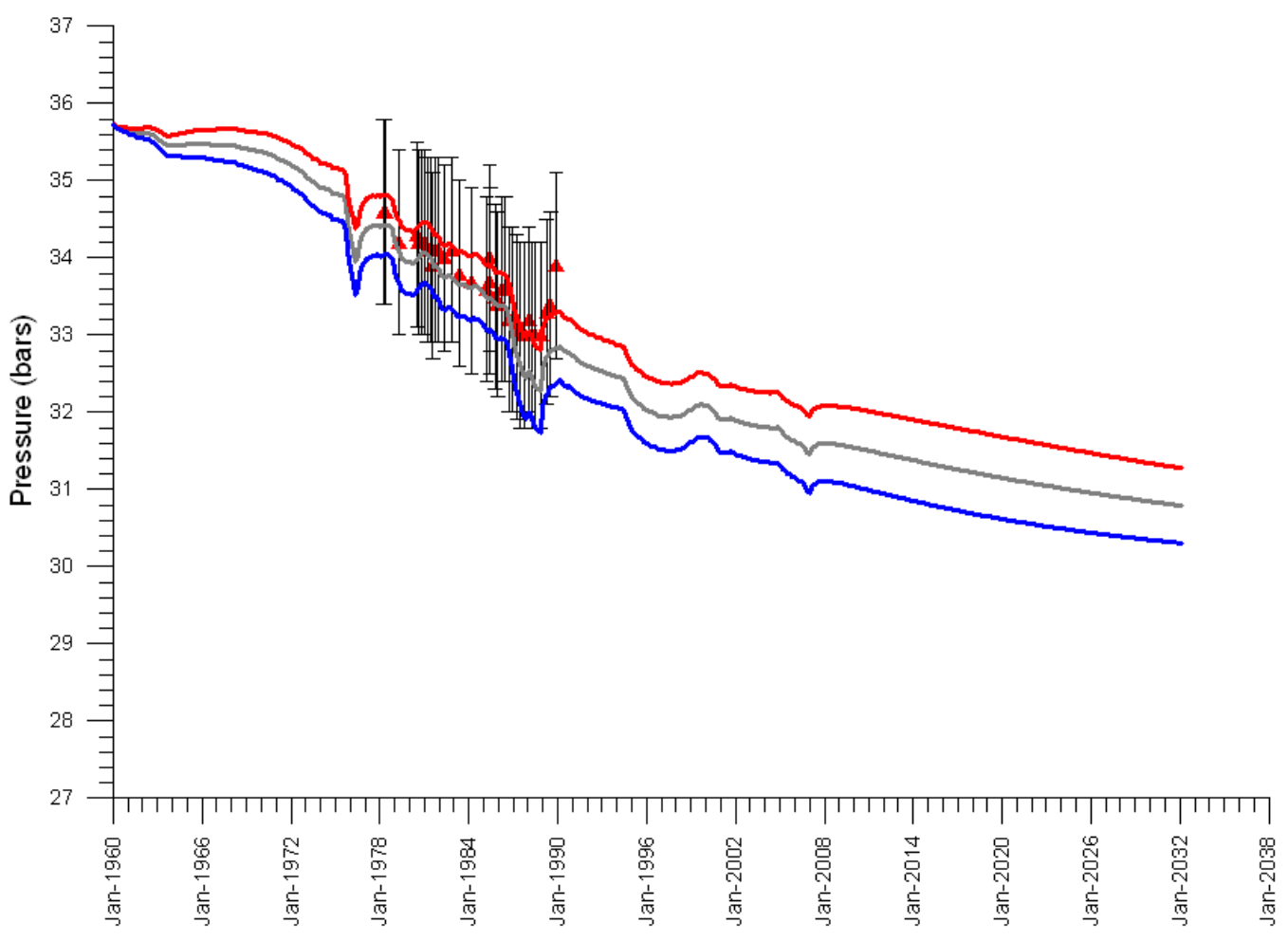

Fig. 12. Prediction and linear uncertainty propagation analysis for the Pauzhetsky model as applied to Well \#124 pressure data estimates based on leveling and temperature log data.. Lines: computed mean and 95\% confidence interval; solid triangles: observed data, There are no measured pressure data after 1988, when boiling conditions were reached at the observation point. Bars represent the 95\% confidence intervals for the observed pressure data, assuming a standard deviation of $\sigma=3$ bars. 


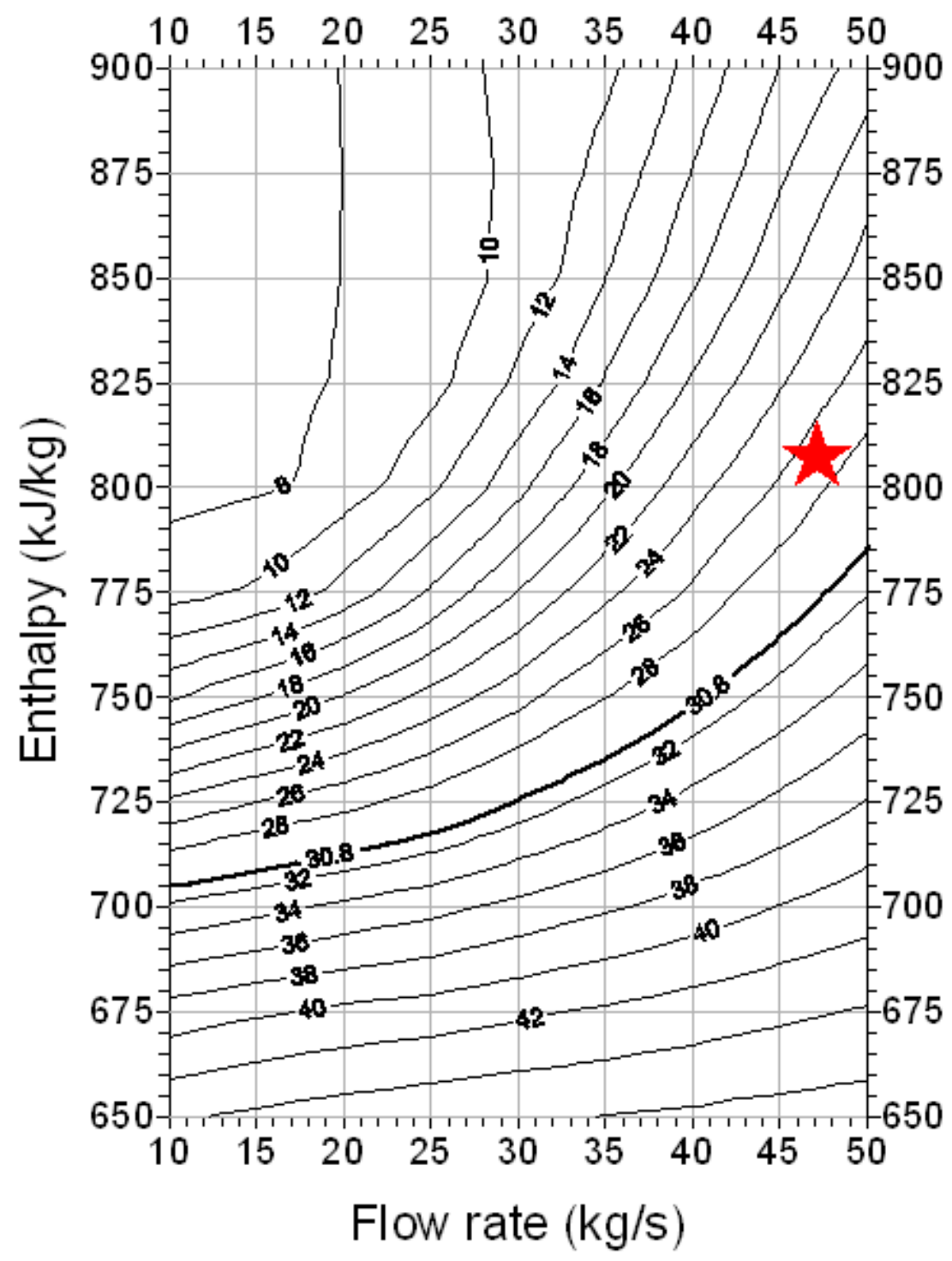

Fig. 13. Bottomhole pressure of Pauzhetsky Well \#123 (given in bars) as a function of flow rate and fluid entalphy as calculated by the computer program HOLA; the assumed wellhead pressure was 3.83 bars. Thick line: grid-block pressure of 30.8 bars; star: computed October 2006 bottomhole conditions for the well. 


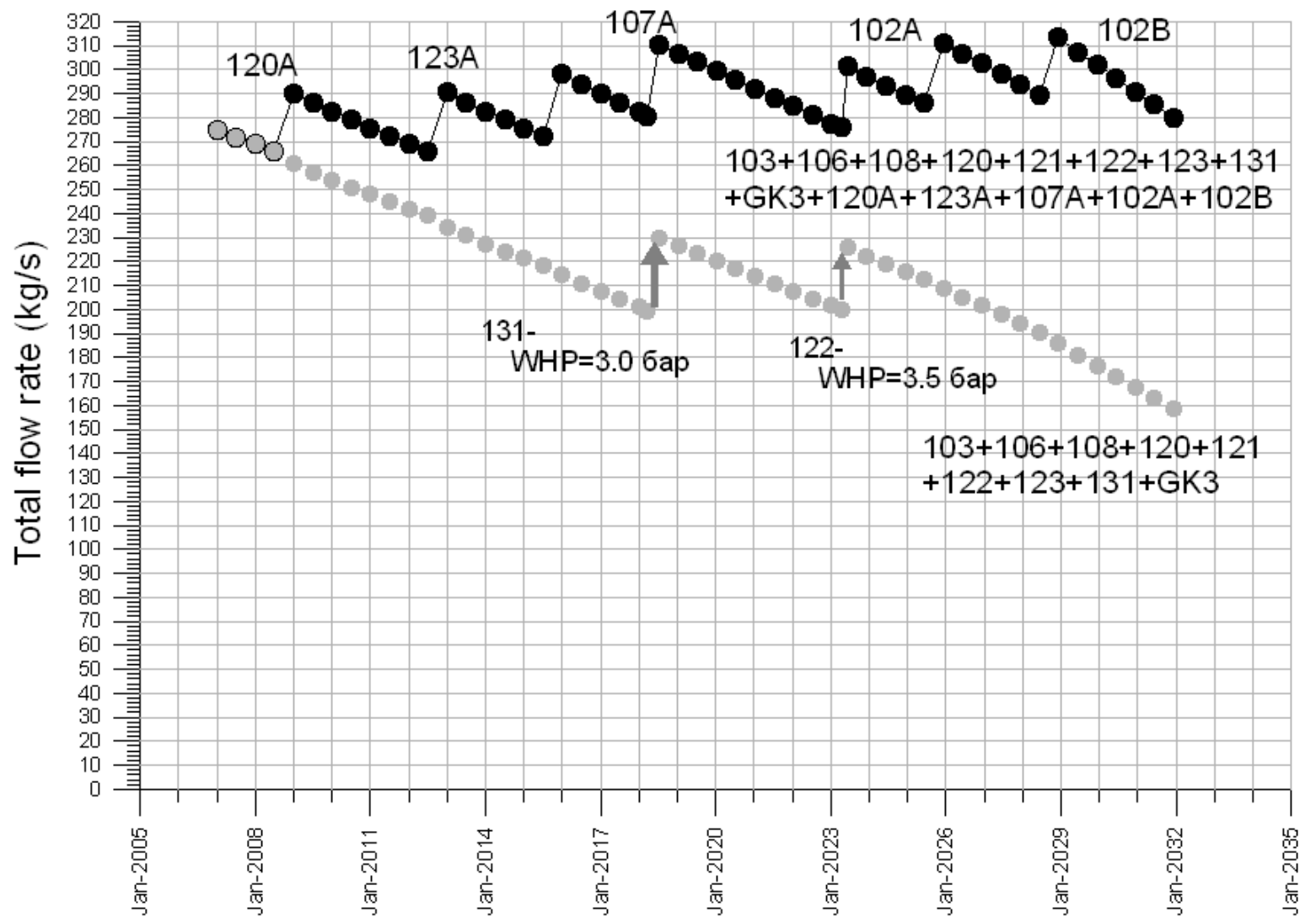

Fig. 14. Predicted total flow rates for Pauzhetsky Wells 103, 106, 108, 120, 121, 122, 123, 131, GK3, 120A, 123A, 107A, 102A, 102B for the exploitation period 2007-2032. The lower graph shows production rates using only wells that existed in December 2006. 


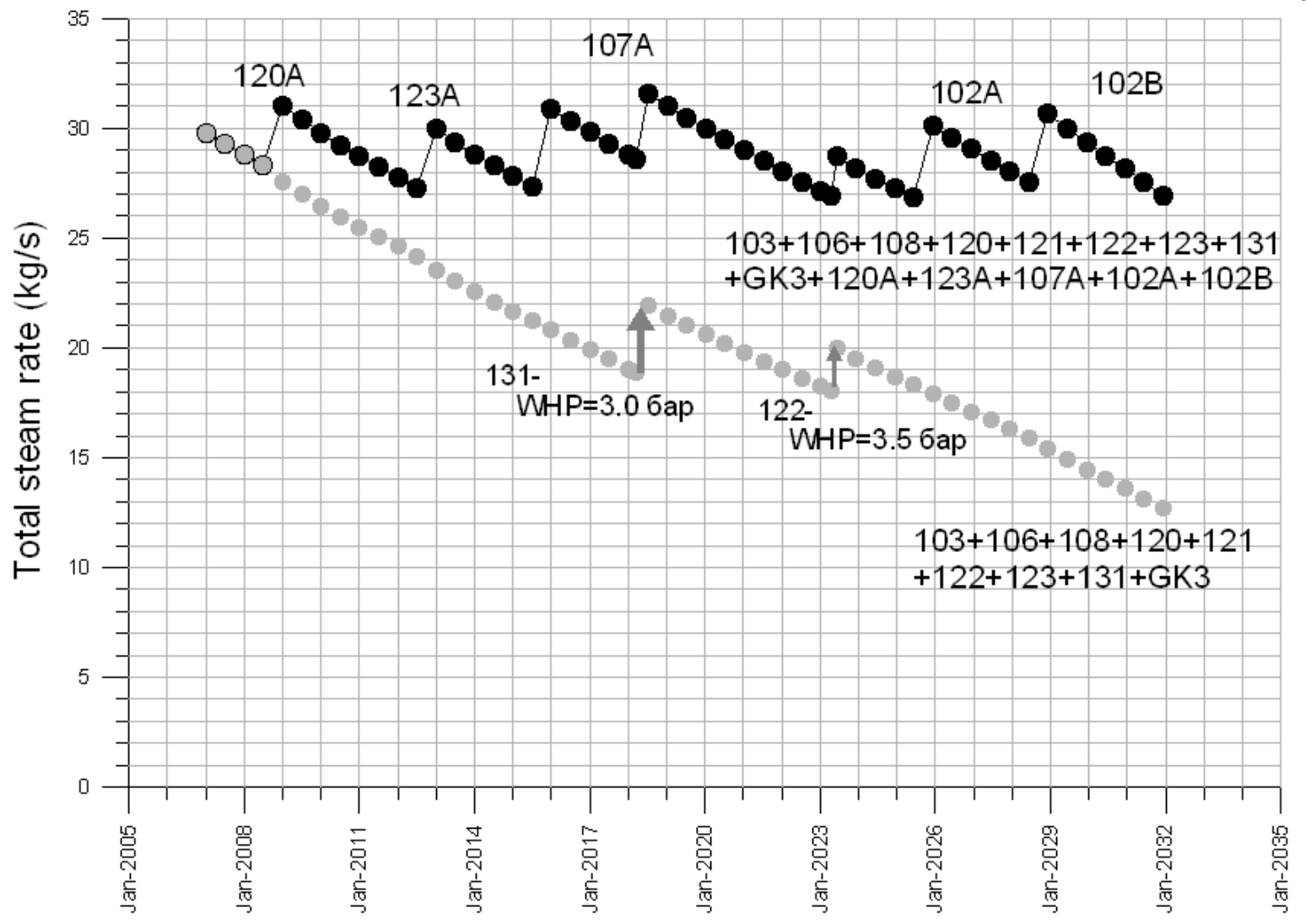

Fig. 15. Predicted total steam rate for Pauzhetsky Wells 103, 106, 108, 120, 121, 122, 123 , 131, GK3, 120A, 123A, 107A, 102A, and 102B for the exploitation period 2007-2032. The steam rate is calculated at the separation pressures given in Table 4. The lower graph shows steam rates using only wells that existed in December 2006. 